NBER WORKING PAPER SERIES

\title{
MEASURING THE EFFECTS OF FIRM UNCERTAINTY ON ECONOMIC ACTIVITY: NEW EVIDENCE FROM ONE MILLION DOCUMENTS
}

\author{
Kyle Handley \\ J. Frank Li \\ Working Paper 27896 \\ http://www.nber.org/papers/w27896 \\ NATIONAL BUREAU OF ECONOMIC RESEARCH \\ 1050 Massachusetts Avenue \\ Cambridge, MA 02138 \\ October 2020
}

We have received helpful comments from Nick Bloom, Cheng Chen, Steve Davis, Doireann Fitzgerald, Davide Furceri, Tarek Hassan, E. Han Kim, Yao Lu, Indrajit Mitra, John Rogers, Simon Sheng, Jagadeesh Sivadasan, Steven Terry, and Toni Whited; our discussants Scott Baker, Erica X. N. Li and Xinyan Yan; and seminar participants at Michigan, RIETI (Japan), the Conference on Uncertainty and Economic Activity at Renmin University, NBER Summer Institute, Stanford SITE, Stanford Hoover, CAED, Econometric Society Summer Meeting, Tsinghua PBC, and CICF. This research was conducted while the authors were Special Sworn Status researchers at the Michigan Census Research Data Center. Any opinions and conclusions expressed herein are those of the authors and do not necessarily represent the views of the U.S. Census Bureau. All results have been reviewed to ensure that no confidential information is disclosed. We thank Clint Carter for assistance and timely disclosure review of all results. Rohit Singla at Michigan provided invaluable assistance with computing resources. The views expressed herein are those of the authors and do not necessarily reflect the views of the National Bureau of Economic Research.

NBER working papers are circulated for discussion and comment purposes. They have not been peer-reviewed or been subject to the review by the NBER Board of Directors that accompanies official NBER publications.

(C) 2020 by Kyle Handley and J. Frank Li. All rights reserved. Short sections of text, not to exceed two paragraphs, may be quoted without explicit permission provided that full credit, including $\odot$ notice, is given to the source. 
Measuring the Effects of Firm Uncertainty on Economic Activity: New Evidence from One Million Documents

Kyle Handley and J. Frank Li

NBER Working Paper No. 27896

October 2020

JEL No. D81,E22,E32

\begin{abstract}
We construct a new measure of firm-level uncertainty from analyzing the text of mandatory reports filed with the U.S. Securities and Exchange Commission. Using firm and establishment level panel data on investment margins and employment dynamics, we find our uncertainty measure has large effects on investment even after controlling for industry and time-varying shocks. Periods of high firm uncertainty (1) reduce investment rates by $0.5 \%$ and attenuate the response to positive sales shocks by about half and (2) reduce employment growth rates by $1.4 \%$ and the response to positive sales shocks by $30 \%$. Firms are less responsive to demand shocks at the firm level and across establishments within the firm. Consistent with "wait and see" dynamics, uncertainty affects new investment activity, e.g. plant births and acquisition, more than disinvestment margins.
\end{abstract}

Kyle Handley

Ross School of Business

University of Michigan

701 Tappan Street

Ann Arbor, MI 48109

and NBER

handleyk@umich.edu

J. Frank Li

Stanford University

210 Panama Street

Stanford, CA 94305

jfli@stanford.edu 


\section{Introduction}

Uncertainty can be defined in theory to carefully and specifically encompass aggregate, industry, or firm-level shocks. But measuring uncertainty, especially at the firm-level, is difficult in practice, both for firms and the economists who study them. Our approach to quantifying firm uncertainty rests on a simple hypothesis: if firms say they are uncertain, then we can take their word for it literally. To test this, we measure how frequently firms use variations of the word "uncertainty" in mandatory reports filed with the U.S. Securities and Exchange Commission (SEC). We summarize about one million documents from 1994-2016 and build a new panel database of firm-level, time-varying uncertainty measures. With these measures in hand, we then ask three important questions: (1) should we take firm declarations of "uncertainty" at face value; (2) how important are fluctuations in firm-level uncertainty for investment activities; and (3) does the firm-level variation in uncertainty explain micro fluctuations independently of aggregate and industry uncertainty measures?

A growing body of recent work investigates the effects of uncertainty on economic activity. The dynamics of uncertainty and investment have been theoretically understood for some time (cf. Bernanke, 1983; Dixit, 1989; Abel and Eberly, 1994). In the presence some form of partially irreversible costs, firms will delay projects and be less responsive to shocks when uncertainty about future business conditions is high. Some research links reduced investment to realized or forecasted stock return volatility using firm-level data (Leahy and Whited, 1996; Bloom et al., 2007). Responses to uncertainty can extend beyond capital investments to affect hiring decisions when labor adjustment or search and matching costs are high (Bloom, 2009; Schaal, 2017). It can also affect aggregate export dynamics (Novy and Taylor, Forth.) or firm decisions to enter and invest in new export markets (Handley, 2014; Handley and Limão, 2017).

Understanding and measuring uncertainty at the firm-level is important. Recent theory and evidence suggest that idiosyncratic shocks to particular firms play an important role in observed aggregate fluctuations (Gabaix, 2011), but evidence on uncertainty shocks is limited and mixed. Bachmann and Bayer $(2013 ; 2014)$ suggest that small shocks to firm productivity are important to explaining pro-cyclical productivity dispersion using German firm-level data, but are not a driver

of major business cycles. In contrast, Bloom et al. (2018) find evidence that micro uncertainty rises 
in recessions and that uncertainty shocks lead to reductions in GDP, productivity and reallocation in a heterogeneous firms DSGE model. To better understand these dynamics, we build firm-level measures of uncertainty from textual analysis of company reports that we can use to explore both firm and industry investment dynamics. Thus, we can explore firm-specific fluctuations in uncertainty in a long panel against performance outcomes that include investment, employment growth, and establishment dynamics using data from both COMPUSTAT and the U.S. Census firm and establishment microdata.

Constructing quantitative measures of uncertainty, even at the aggregate level, is fraught with difficulty. This complication was recognized by Keynes (1937), who noted that firms must carry on with investment and employment decisions despite the difficulty in quantifying their uncertain knowledge of the future ${ }^{1}$ More recently, Jurado et al. (2015) show that many common proxies for uncertainty may reflect a mixture of first moment shocks and other sources of variation unrelated to fundamental uncertainty. For example, aggregate proxies such as the CBOE Volatility Index (VIX) measure the volatility of the S\&P 500 index implied by equity call options on its underlying components. But the prices of these options and their implied volatility can move substantially even if the underlying fundamentals of the business enterprise are unchanged. Nevertheless, these derived uncertainty proxies operate like uncertainty measures in some empirical work. Barrero et al. (2017) and Stein and Stone (2013) find that increases in implied volatility derived from equity options reduces hiring and investment. Unfortunately, traded equity options for large number of public firms simply don't exist, including components of the S\&P 500 Index.

Other measures at the firm level are qualitative and derived from surveys of firms or professional forecasters. What these measures lack in quantitative precision is offset, at least partially, by the fact that they are sourced from managers, insiders, and professionals with a detailed knowledge of specific companies or industry sectors. For example, the Federal Reserve Board's Greenbook and other proprietary professional forecasts contain significant narrative components. Sharpe et al. (2017) show the tonality of Fed Board forecasts has predictive power for GDP growth and

\footnotetext{
${ }^{1}$ Writing about uncertainty over the prospect of war, copper prices, and product obsolescence, Keynes (1937) remarked: "About these matters there is no scientific basis on which to form any calculable probability whatever. We simply do not know. Nevertheless, the necessity for action and for decision compels us as practical men to do our best to overlook this awkward fact and to behave exactly as we should if we had behind us a good Benthamite calculation of a series of prospective advantages and disadvantages, each multiplied by its appropriate probability, waiting to be summed." (p. 214)
} 
inflation. Moreover, financial market participants and consumers must value this information given that they continue to pay for the analysis. Similarly, surveys of managers should capture the uncertainty about future business conditions by the decision-making economic agents within the firm. Bachmann et al. (2013) find in German and U.S. data that disagreement in forecasts precede reductions in output driven by "wait-and-see" dynamics that are short-lived in Germany and more persistent in the United States.2 Guiso and Parigi (1999) use survey data on Italian firms and find that uncertainty about future demand reduces investment. More recently, Bloom et al. (2017) describe evidence from the Management and Organization Practices Survey (MOPS) on the business expectation of managers in the manufacturing sector. They find managers responses to questions about future sales and production expectations are logically consistent and strongly correlated with realized first and second moments in the data.

Our approach measures business uncertainty by analyzing the documents filed with the U.S. Securities and Exchange Commission (SEC). All publicly traded companies are required to file form $10-\mathrm{K}$ annually and form 10-Q quarterly. These forms report the firm's activities and financial information to investors, shareholders and the public $3^{3}$ For each document we measure the frequency of the word "uncertainty" and its variations relative to the total number of words to construct a firm-specific Company Reported Uncertainty IndeX, or CRUX. There are several advantages to this measure relative to previous work. First, the basic index methodology is consistent with aggregate text-based measures, e.g. the Baker et al. (2016) economic policy uncertainty index, but applied at the firm-level. Second, it relates to work using survey data to extract firms' subjective probability distributions. Our source data is not a survey with specific questions, but we build the measure from what is effectively a mandatory census of all publicly traded companies that includes a mixtures of free-form written responses and financial information. Third, our methodology can easily be extended to longer time series and used in subsequent research as new document filings are added to the EDGAR database.

We verify our measure and estimate importance of firm-level uncertainty by linking the firmlevel CRUX to microdata on investment and employment from two sources: (1) publicly available

\footnotetext{
${ }^{2}$ Morikawa (2016) also uses forecast survey data and finds a negative relationship between uncertainty and investment.

${ }^{3}$ The SEC phased-in electronic filing from 1994-1996 and makes the forms available through EDGAR, the Electronic Data Gathering, Analysis, and Retrieval system. We describe nature of the forms and our methods in the data section.
} 
investment and employment data in COMPUSTAT and (2) the confidential U.S. Census microdata on firm and establishment dynamics we construct from the the Longitudinal Business Database (LBD) and detailed investment data from the Annual Survey of Manufactures (ASM) and the Census of Manufactures (CM). This rich microdata, especially U.S. firm and establishment datasets, allow us to control for a variety of confounding shocks. Moreover, our measure is not computed from volatility or dispersion in firm-level outcomes (e.g. employment, productivity, sales, etc.) that may be endogenous to firm decisions.

We find compelling evidence that firm-level uncertainty reduces investment, broadly defined, and makes firms less responsive to demand shocks. As a first pass, we demonstrate this in Figure 1 . where we plot a non-parametric bin scatter of investment relative to our CRUX measures that is clearly negative. Of course, our index may capture a mixture of first and second moment shocks. For example, suppose firms cite uncertainty when times are bad as an excuse for poor performance. We find first moment shocks don't drive our results and numerous checks suggests we are capturing variation in second moment shocks. First, even after controlling for time invariant firm effects and industry-by-year unobservables, our measure has substantial residual variation for identification. So we can then estimate first-order investment delay effects from uncertainty even after including a battery of first moment controls for firm and industry shocks. Second, and perhaps more importantly, we can also test for second-order caution effects: the attenuated response of investment to demand shocks when uncertainty is high. In Figure 2, we show precisely this result in a bin scatter of the investment response to a sales shock for high and low levels of our uncertainty measure. Third, we leverage the establishment level variation within firms to control for unobserved firm-level first moment shocks through a complete set of firm-year fixed effects. Thus we can identify caution effects of uncertainty through the firm's reallocation of investment activity across establishments. Within firm reallocation in response to uncertainty is non-trivial in the data and has a strong theoretical basis in the investment under uncertainty literature (cf. Bloom, 2009; Bloom et al., 2007).

A final concern is that the Form 10-K and other associated company reports do not contain accurate and reliable information disclosures. There is a broader empirical literature on textual analysis, to which we contribute, that suggests this is not the case. First, compliance is mandatory and there are penalties for making false or misleading statements. Second, a number of studies using 
contextual information for SEC filings surveyed in Loughren and MacDonald (2016) and Li (2010) find that language, tone, sentiment and specific words are predictive of firm behavior, identify important firm characteristics, or explain other economic and financial outcomes. For example, Hoberg and Phillips (2016) construct new measures of product characteristics and industry network linkages; Bodnaruk et al. (2015) use 10-K text to measure financial constraints; Buehlmaier and Whited (2018) show textual measures of financial constraints help explain equity returns; Avramov et al. (2016) show contextual measures of downside risk affect numerous corporate policies; and Li et al. (2013) develop measures of market competition consistent with existing measures that contain additional new information. Third, it's possible that managers make persistent forecast errors and under- or over-estimate volatility as shown by Ben-David et al. (2013). But even if we concede that firm statements about uncertainty are revealed ex post to be misguided or driven by cognitive biases (see Kahneman, 2003) they still reflect thinking that can affect managerial decisions and firm outcomes in important ways. Our task is to understand and empirically quantify that channel.

We contribute to a broader literature that uses text-based measures of uncertainty and economic behavior. The seminal work on textual uncertainty measures is the Baker et al. (2016) index of economic policy uncertainty constructed counts of words in major news outlets normalized by the total number of news articles within a given time period. Their measure is correlated with major episodes of policy uncertainty and associated with lower investment rates, hiring, and downturns in GDP and investment. Hassan et al. (2019) use a pattern-based sequence-classification method to distinguish political vs accounting discussions to generate measures of firm-level political uncertainty derived from quarterly earnings conference calls. Hansen et al. (2018) use topic modeling to study the effect of transparency on open market committee meeting discussions between experienced and less experienced members ${ }^{4}$

The rest of the this paper is organized as follows. In Section 2, we describe our underlying data source of SEC mandatory filings and the construction of the uncertainty index. Section 3 describes our estimation strategy and results. Section 4 concludes.

\footnotetext{
${ }^{4}$ Similarly, Shepotylo and Stuckatz (2018) measure trade policy uncertainty in Ukraine and the firm-level response of FDI and export market entry and exit relative to the likelihood of trade agreement with the European Union.
} 


\section{Measurement and Data}

We first describe how we process the text and discuss some contextual examples. We then discuss both our firm-level public data sample, i.e. COMPUSTAT, and our confidential microdata sample with establishment level investment and employment dynamics.

\subsection{Measuring Uncertainty in Context}

To measure uncertainty, we use the text of SEC reports from the EDGAR Database. All public domestic firms are required to make reports to U.S. Securities and Exchange Commission (SEC) on a regular basis. For example, the firms must submit annual reports (Form 10-K), quarterly reports (Form 10-Q) and current reports (Form 8-K) which must comply with certain disclosure requirements.

We parse and match SEC EDGAR reports against a dictionary of English words from all 10K, 10-Q reports and their amendments each year. Our entire textual sample includes 1,000,313 documents - all 10-Q and 10-K forms, their variations, and amendments - filed by 41,418 firms from 1994 to 2016. Each filing can be exactly identified by three factors: a Central Index Key (CIK), filing date, and filing type (10-K, 10-Q or amendments). The CIK identifier is used to match with data from COMPUSTAT. When two companies merge or a company changes their name, the CIK of the surviving/new entity can be associated with the new name by updating the company profile in the EDGAR database.

We count the total number of uncertain words in each document from the list \{uncertain, uncertainty, uncertainties, uncertainly\}. We then aggregate by firm CIK identifiers (indexed by $i$ ) and filing period (year and quarter, indexed by $t$ ) over all the forms to obtain total Total uncertain words $i t$. We normalize this count by the total number of meaningful words to compute the Company Reported Uncertainty Index (CRUX) by firm and filing period

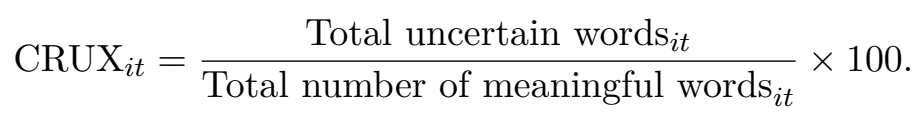

The denominator, total number of meaningful words, counts all the words that are present in the filing, but excludes all the stop words, e.g. 'a', 'an', 'the', etc. from the total count 5 We scale the

\footnotetext{
${ }^{5}$ We provide a list of these words in the appendix.
} 
measure up by 100 so that it measures percentage point frequency.

For the one million parsed SEC EDGAR documents, several statistics are notable (see Appendix Table A2 for details). First, the average document contains 4.4 words that are forms of the word "uncertainty." The median count is 3 and there is a high variability across documents ranging from zero to 133 with a standard deviation of 5.7. In part, this is due to commingling quarterly 10-Q and annual 10-K reports along with mixing larger firms that have complex business structures and smaller firms that may have only a few product lines. Because of the variation across form type, filing frequency, and firm types we aggregate total uncertain words and total meaningful words by year. The stop word adjustment drops the average word count in a document from over 19,000 to just over 11,000 words. Our results are robust to normalization by all words in a document, but slightly less precise.

\subsection{Examples in Context}

The reason we focus exclusively on "uncertain" words is that we intend to measure subjective expressions of uncertainty. Other words may be of interest for different applications, but do not have the same connotation. For example, words such as "risk" may just indicate lines of business, i.e. "risk management firm" and insurance companies, or describe objective and measurable risks that a firm has taken. ${ }^{6}$ Moreover, firms may generally have a positive outlook about future sales or profits, an expectation about the future, but still express uncertainty around that outlook.

The evidence that we are measuring some degree of uncertainty ultimately lies in the empirical results we discuss in Section 3. But to help understand the source of our measure for some wellknown companies, we provide the following three contextual examples:

Apple Computer: global and regional shocks

"The Company's operations and performance depend significantly on global and regional economic conditions. Uncertainty about global and regional economic conditions poses a risk as consumers and businesses postpone spending in response to tighter credit, higher unemployment, financial market volatility, government austerity programs, negative financial news, declines in income or asset values and/or other factors." (Apple, 2013 10-K, Risk Factors)

\footnotetext{
${ }^{6}$ We show in robustness checks that a measure based on "risk"-related words does not have a robust impact on investment.
} 
Apple describes a number of traditional sources of uncertainty that are both regional and global. Some of these may be aggregate or industry shocks that could affect all firms. Nevertheless, they may be more important to Apple because it operates in multiple jurisdictions and sells products all over the world. For example, the volatility in the Dollar to Renminbi exchange rate may indirectly affect nearly all U.S. firms. But it's more likely that firms reference that uncertainty if it is important to their business lines. So even if these reported global uncertainties are simply Apple's report of aggregate shocks, they are being mentioned because they have some specific relevance to Apple's outlook on the future.

General Motors: unspecified generic uncertainty and risk

"We face a number of significant risks and uncertainties in connection with our operations. Our business, results of operations and financial condition could be materially adversely affected by the factors described below." (GM, 2010 10-K, Risk Factors)

In other reports, the description is more similar to General Motors. Uncertainty specific to its operations is mentioned, but not attributed to specific source. Our index measure will count this mention of uncertainty. If it doesn't contain meaningful information, then our ultimate empirical results should find little effect.

Wal-Mart: litigation uncertainty

"However, because of the uncertainty of the outcome of the appeal from the District Courts certification decision, because of the uncertainty of the balance of the proceedings contemplated by the District Court, and because the Company's liability, if any, arising from the litigation, including the size of any damages award if plaintiffs are successful in the litigation or any negotiated settlement, could vary widely, the Company cannot reasonably estimate the possible loss or range of loss which may arise from the litigation." (Walmart, 2006 first 10-Q, Financial Information)

We highlight the Walmart disclosure as it concerns litigation uncertainties about potential financial liabilities that are difficult to objectively quantify. These discussions take place in the financial information section of a quarterly 10-Q. Such discussion would be missed if we focused only on annual 10-K filings and the Risk Factors section of the report. 


\section{Firm-level Estimation and Quantification}

We employ three different data sources at the firm-level to estimate panel regressions of the effect of uncertainty on investment and employment growth. First, we use total corporate investment from COMPUSTAT to estimate the broader effects of firm uncertainty on investment across all sectors of the economy. Second, we turn to detailed establishment level investment data for the manufacturing sector from the Census Bureau's Annual Survey of Manufactures and Census of Manufactures. The latter investment data are closely aligned with canonical models of investment under uncertainty. Third, we measure the establishment dynamics within the firm using the LBD.

\subsection{Identification and Estimation Approach}

We discuss our our identification strategy in two steps. First, we describe the requirements to identify effects of firm-specific exposure to uncertainty and show they hold in our data. Second, we discuss our estimation equation and how we handle threats to identification.

\subsubsection{CRUX Variation}

To fix ideas, we let $\operatorname{CRUX}_{i t}=f\left(\mu_{i t}, \sigma_{i t}\right)+\varepsilon_{i t}$. This makes explicit that our measure is a function of firm-specific uncertainty $\sigma_{i t}$, possible first moment shocks $\mu_{i t}$, and measurement error $\varepsilon_{i t}$. We then take a first order Taylor approximation around firm-level mean deviations in $\bar{\mu}_{i}$ and $\bar{\sigma}_{i}$ to write

$$
\operatorname{CRUX}_{i t}=f\left(\bar{\mu}_{i}, \bar{\sigma}_{i}\right)+f_{\mu}\left(\bar{\mu}_{i}, \bar{\sigma}_{i}\right)\left(\mu_{i t}-\bar{\mu}_{i}\right)+f_{\sigma}\left(\bar{\mu}_{i}, \bar{\sigma}_{i}\right)\left(\sigma_{i t}-\bar{\sigma}_{i}\right)+e_{i t}
$$

where $e_{i t}$ is a composite of higher-order approximation and measurement error. We assume that $f_{\sigma}(\cdot)$ is positive so that CRUX $_{i t}$ captures a relative ranking of more or less uncertain states across firms. The approximation also makes clear that identification requires within firm, time variation in uncertainty, i.e. $\operatorname{Var}\left(\sigma_{i t}-\bar{\sigma}_{i}\right)>0$. Otherwise, differences across firms may be driven entirely by time-invariant uncertainty (and first moment) differences in a firm's business environment.

Given these requirements, one might worry that corporate reports only reflect aggregate fluctuations and differences in firm-invariant characteristics in most years. To address this, we regress CRUX on a large set of fixed effects for aggregate time, industry, and firm components and report 
our results in Table 17 Column (1) reports the R-squared when CRUX is regressed one-by-one on a set of fixed effects for year, industry, industry-year, and firm fixed effects in each row. The largest components are a firm effect, $49 \%$ of variation, and time effect, $21 \%$ of variation. Industry effects contribute a small amount unless they are interacted with time effects, i.e. industry-year shocks. In Column (2) we additively regress CRUX on time fixed effects, industry fixed effects, industry-year fixed effects, and then firm fixed effects. The remaining residual variation in the CRUX measure is $37 \%$ after controlling for firm and industry-year fixed effects. So clearly the CRUX measure captures aggregate fluctuations and firm characteristics, but still retains significant amount of residual variation at firm-year level. The latter variation is used for identification in all our baseline firm and establishment level regressions.

\subsubsection{Estimation Equation}

Next we turn to our baseline empirical model to estimate the effect of uncertainty on investment and employment. We have panel data for firms (using the LBD and COMPUSTAT) and establishments (ASM/CM) over time.

We use several different dependent variables $\Delta y_{i t}$ that are direct investment measures or related outcomes. Our baseline estimating equation is

$$
\begin{aligned}
\Delta y_{i t}= & \lambda \operatorname{CRUX}_{i t}+\eta \operatorname{CRUX}_{i t} \cdot \Delta \log (\text { sales })_{i t-1}+\beta^{\text {sales }} \Delta \log (\text { sales })_{i t-1} \\
& +\boldsymbol{\beta} \cdot \boldsymbol{X}_{i t-\mathbf{1}}+\alpha_{i}+\alpha_{t}+\epsilon_{i t} .
\end{aligned}
$$

For investment, the dependent variable is investment rates (corporate, equipment, structures) computed as the log change in the capital stock. We also compute growth rates of establishment and employment within the firm that are decomposed into contributions from births, deaths, continuers, etc. We include firm fixed effects $\alpha_{i}$ and time fixed effects $\alpha_{t}$ to identify idiosyncratic uncertainty, as discussed above, and any other unobservable firm characteristics and aggregate shocks that might influence $\Delta y_{i t}$.

Our primary interest is on the two RHS terms that contain the CRUX measure. First, we include $\mathrm{CRUX}_{i t}$, the contextual measure of uncertainty from SEC reports described above 8 The

\footnotetext{
${ }^{7}$ These results use the matched SEC EDGAR - COMPUSTAT sample we describe below.

${ }^{8}$ We take $\mathrm{CRUX}_{i t}$ instead of $\mathrm{CRUX}_{i, t-1}$ because our measure is based on date of filing, which reports mixture of
} 
coefficient on $\lambda$ measures first order effect of uncertainty on the outcome. In the presence of any non-convex adjustment costs or irreversible sunk costs of decisions, we expect to find a "delay" effect whereby new investment, capital improvements, establishment births, or job creation are reduced when uncertainty is high. So we predict that $\lambda<0$. We also include the interaction term $\operatorname{CRUX}_{i t} \cdot \Delta \log (\text { sales })_{i t-1}$ to estimate a second order "caution" effect in response to shocks. Specifically, it measures how firms respond to demand shocks under uncertainty. Caution effects will attenuate investment or growth response when uncertainty is high. Job growth and investment typically increase in response to sales shocks so that $\beta^{\text {sales }}>0$. So we predict attenuation from the caution effect such that $\eta<0$.

\subsubsection{Identification}

The main threat to identification of caution and delay effects is that CRUX $_{i t}$ may also capture first moment shocks, rather than uncertainty. Here, we again refer to equation (1), where the dependence on first moments is explicit. The first two solutions are econometric and the third is more subtle. Let the first moment parameter be decomposed into firm, time, and firm-time components as $\mu_{i t}=\bar{\mu}_{i}+\bar{\mu}_{t}+\tilde{\mu}_{i t}$.

First, our dependent variable and sales growth are already differenced. We also include firm fixed effects $\left(\alpha_{i}\right)$ that absorb persistent firm shocks to $\mu_{i}$, firm idiosyncratic growth trends, and the propensity by specific firms to use "uncertainty"-type words more frequently. We also include year fixed effects $\left(\alpha_{t}\right)$ and ultimately industry-year effects that absorb industry and aggregate demand shocks in $\mu_{t}$.

Second, we include in the the vector $\boldsymbol{X}_{i t-1}$ a set of first moment controls that proxy for $\tilde{\mu}_{i t}$ : average Tobin's Q $\left(\log \left(q_{i t-1}\right)\right)$ to a proxy of firms' investment opportunities, lagged log sales growth $\left(\Delta \log (\text { sales })_{i t-1}\right)$ to control for firm level demand shocks, and squared log sales growth to capture nonlinear effects.

Third, finding cautionary effects is an important piece of evidence in favor of the CRUX as a firm-level uncertainty measure. Suppose firms use "uncertainty" as a catch all term, or even an excuse, to describe bad demand or cost shocks when $\mu_{t}<0$ or $\tilde{\mu}_{i t}<0$. Likewise, the same firm may not mention uncertainty at all after a positive sales shock, e.g. implicitly or explicitly claiming firm information in the previous year or quarter and forward looking statements about the future. 
that "we knew it all along." That would negatively bias our estimate toward $\lambda<0$. But the same would not hold for the predicted, negative cautionary effect of $\eta<0$. To see this, suppose a firm gets a negative sales shock, $\Delta \log (\text { sales })_{i t-1}<0$, and responds by declaring that the world is a very uncertain place, i.e. driving up CRUX $_{i t}$. If we suppose CRUX contains only first moment shocks, then it is an inverse proxy measure of demand or sales; we would spuriously estimate $\hat{\lambda}<0$. But this also means that the sales growth and CRUX interaction term would be the product of a negative sales shock and the inverse demand proxy that is large and positive. If we maintain our predictions that $\lambda<0$ and $\beta^{\text {sales }}>0$ in this environment, we predict $\eta>0$, i.e. investment declines more when negative sales shocks are large. The latter should only occur if the CRUX $_{i t}$ variation is driven, in whole or in part, by first moment shocks. In our results below, we clearly reject $\eta>0$ and this suggests that on average the CRUX measure is capturing some element of firm-specific uncertainty.

A related concern is that uncertainty is endogenously generated by low employment or investment growth. Because our panel data allows us to control for many of these shocks through fixed effects and we include a number of first moment controls, this issue is not likely to be severe in our application. Moreover, if the feedback from outcomes to uncertainty were strong, then we should expect CRUX to be negatively correlated with all investment and decision margins within the firm. When we decompose establishment and employment growth margins (birth, death, continuers, acquisition, and divestiture) we only find an effect on new investment margins and those that are likely to have higher costs of adjustment. That latter is consistent with the theory of investment under uncertainty and we discuss this further in section 3.5 .

Given the set of fixed effects we employ and the examples noted in section 2.2, it's important to be careful interpreting the resulting estimates. To see this, note that our linear approximation of CRUX in (1) applies to each firm $i$. The coefficient on uncertainty exposure $f_{\sigma}\left(\bar{\mu}_{i}, \bar{\sigma}_{i}\right)$ is firm specific. This can matter in the estimation if we want to know whether the effect of uncertainty on an outcome is a firm-specific reaction to its exposure to aggregate uncertainty or a response to its own firm-specific uncertainty. We operationalize this by letting $\sigma_{i t}=\sigma_{t}^{A}+\tilde{\sigma}_{i t}$. We can consider $\sigma_{t}^{A}$ aggregate uncertainty and $\tilde{\sigma}_{i t}=\tilde{\sigma}_{i t}-\sigma_{t}^{A}$ are firm-level deviations.

In our baseline, we estimate the average partial effect of CRUX on an outcome. The estimated $\hat{\gamma}$ is the average of firm level heterogeneous responses given by $\gamma_{i} \times \operatorname{CRUX}_{i t}$ and therefore $\gamma=E\left(\gamma_{i}\right)$. 
But firms may respond heterogeneously to aggregate and firm specific shocks: $\gamma_{i}^{A} \sigma_{t}^{A}+\tilde{\gamma}_{i} \tilde{\sigma}_{i t}=$ $\left(\gamma_{i}^{A}-\tilde{\gamma}_{i}\right) \sigma_{t}^{A}+\tilde{\gamma}_{i} \sigma_{i t}$. If $\tilde{\gamma}_{i} \approx 0$ and $E\left(\gamma_{i}^{A}\right)<0$, then we would still estimate a negative effect of uncertainty because of heterogeneity in how firms respond to aggregate uncertainty. Alternatively, if $\gamma_{i}^{A}=\gamma^{A}$, then it is absorbed by time or industry-time fixed effects out. In that case $\gamma=E\left(\tilde{\gamma}_{i}\right)$ is identified from the firm response to its own uncertainty. Using our rich firm-level data we can rule out our results are driven purely by heterogeneity in response to aggregate or industry-specific uncertainty. After discussion our baseline results, we return to measurement and estimation of common shock responses in section 3.6 .

\subsection{Firm and Establishment Level Data}

Our firm or establishment level outcomes are drawn from the COMPUSTAT database and confidential microdata from the U.S. Census.

\subsubsection{COMPUSTAT}

We use the COMPUSTAT database to obtain firm information on balance sheets, cash flow and sales. We match the CRUX measure with COMPUSTAT through the firm identifier, CIK, and year from fiscal years ending from 1994 to 2016. After removing missing dependent and independent variables, we have over 93,000 observations on over 10,000 firms.

We measure the investment rate by taking the log difference of firm level capital stock between two consecutive years, i.e. $\log \left(K_{i t}\right)-\log \left(K_{i t-1}\right)$. Capital stocks are computed through the perpetualinventory method. 9

We capture firms' demand shocks by lagged sales log growth and firms' investment opportunities by lagged Tobin's Q. Specifically, we compute $\Delta \log \left(\operatorname{sales}_{i t-1}\right)=\log \left(\operatorname{sales}_{i t-1}\right)-\log \left(\operatorname{sales}_{i t-2}\right)$. We obtain sales directly from COMPUSTAT and find no significant difference is the following results when we use reported revenues instead. We also calculate squared sales log growth as demand

\footnotetext{
${ }^{9}$ Specifically,

$$
K_{i t}=\pi_{t}\left((1-r) K_{i t-1}+I_{i t-1}\right),
$$

where $\pi_{t}$ is the producer price index ratio between year $t$ and $t-1, I_{i t-1}$ is the capital investment (capx) and the initial capital stock of each firm $K_{i 0}$ is measured by total property, plant and equipment (ppent). The producer price index by commodity for finished goods (capital equipment) is aggregated from seasonally adjusted monthly data. If the value of capital investment is missing for a single year, it is interpolated with the mean of the preceding and following values. We test several alternative measures in the robustness section.
} 
shock might have convex effects on firms' investment or hiring decisions. Our measure of lagged $\log$ Tobin's Q is

$$
\text { Tobin's } \mathrm{Q}=\frac{\text { Market Capitalization }+ \text { Market Value of Liability }}{\text { Total Asset Value }}
$$

We compute market capitalization as common shares outstanding $($ csho $) \times$ price closed at fiscal year $($ prcc_f $f)$. Market value of liability is assumed to be approximately equal to the book value of liability and calculated by total asset (at) - total common/ordinary equity (ceq).

\subsubsection{US Census Microdata}

To study the effects of uncertainty on firms' investment and employment margins in further detail, we rely on Longitudinal Business Database (LBD), Annual Survey of Manufacturing (ASM), and Census of Manufactures (CM) collected by the U.S. Census Bureau.

We rely on the LBD to track employment, firm-identifiers, and establishment dynamics within firms. The LBD is derived from the Census Business Register (BR), covers the entire non-farm private sector, and is compiled from administrative records augmented by survey sources. Firms are defined based on operational control, and all establishments majority owned by a parent firm are included in the parent's activity measures.

Firms identifiers in the LBD are linked to COMPUSTAT and the EDGAR based CRUX measure using the Census COMPUSTAT-BR bridge. This allows us to link financial data and our CRUX measure to the firm and establishment level data in the LBD. Specifically, the bridge provides annual link between a COMPUSTAT CUSIP and firm identifier in LBD. We then link CRUX measure to LBD data through CIK-CUSIP-LBD identifiers for 1994-2014 10

The main variables in the LBD that we use are employment and six-digit industry codes in the North American Industrial Classification (NAICS). We assign consistent NAICS industry codes to establishments using the concordance in Fort and Klimek (2018). For multi-unit firms, we compute employment shares across 3 digit NAICS codes with the firm and assign firm NAICS based on the largest 3 digit industry. The LBD reports total employment in the payroll period containing the week of March 12th. We are interested in how reported uncertainty in CRUX effects employment

\footnotetext{
${ }^{10}$ The COMPUSTAT-BR bridge in our approved project ends in 2011, but we track the matched firms in 2011 through 2014.
} 
dynamics, hiring, and reorganization so matching the CRUX measure to this timing is important. Because annual growth in employment between year $t-1$ and $t$ is March to March, we match this timing using a CRUX measure from the second quarter of year $t-1$ to the first quarter of year $t$.

The firm identifiers in the LBD enable us to compute firm and establishment growth rate measures and to track their entry, exit and ownership changes. Because we have establishmentlevel detail linked to a firm-level uncertainty measure, we can explore within-firm restructuring activity in response to uncertainty. We decompose firm expansions and contractions across several margins. In Appendix Table A1 decompose growth in the number of establishments and net job creation into contributions from establishment births, acquisitions, and continuer expansions and death, divestiture, and continuer contractions.

To obtain high quality data on investment and capital, we use the Annual Survey of Manufactures (ASM) and the Census of Manufactures (CM). We then link our firm level measure directly to establishment measures of total investment broken out into structures and equipment. These databases also provide information on total value of shipments (a sales measure) and manufacturing industry codes (6-digit NAICS). We use these measures to construct log changes in capital stock (investment) and total shipments at the establishment level ${ }^{11}$

\subsection{Firm Level Corporate Investment Results - COMPUSTAT}

Before turning to U.S. Census microdata, we focus on corporate investment measured using COMPUSTAT. We show a robust negative effect on investment from delay and caution effects to our text-based measure of uncertainty.

Our first pass at the firm-level investment data is simple non-parametric evidence of the negative relationship between the investment rate and CRUX. In Figure 1 we plot the bin scatter of corporate investment on CRUX using the optimal bin selection method in Cattaneo et al. (2019). The relationship is clearly negative and approximately (log) linear. We obtain similar results when partialling out controls for sales growth and Tobin's Q, which we explore parametrically below.

We also find evidence of "caution" effects in our second piece of non-parametric evidence. We run a bin scatter of the investment response to standardized sales growth for high and low uncertainty

\footnotetext{
${ }^{11}$ We use a Census Bureau provided measure of capital stock computed using the perpetual inventory method. Details on methodology are in Appendix A of Foster et al. (2016).
} 
subsamples in Figure 1. We predicted that uncertainty would attenuate the response to sales in Section 3.1. Not only do we see a differential in the non-parametric evidence, the confidence intervals for high and low subsamples do not overlap for shocks that are more than one standard deviation above the mean.

Next, we back up the non-parametric results with regression evidence that confirms the negative impact of our uncertainty measure on the corporate investment rate. Table 2 has summary statistics for the regression sample. In Table 3 , column (1) we report the simple regression of firms' log investment rate on CRUX with firm and year fixed effects and find a negative and significant coefficient. This is the delay effect we predicted. The estimated effect is robust to including NAICS 3 digit industry-year effects in column (2). Column (3) adds log sales growth (demeaned within sample) and the interaction term between CRUX and log sales growth. We demean sales growth so that we can interpret the coefficient on CRUX, when we also include the interaction term, as the marginal effect at mean sales growth. We find a positive coefficient on sales growth, as expected, and a negative coefficient on the interaction term. The latter reflects the second-order caution effect we predicted.

We then add other controls for first-moment shocks that are standard in the investment literature. To control for non-linearities in the adjustment of investment to sales, we add the squared log sales growth rate in column (4) and the other coefficients only change slightly. We can also confirm corporate investment has a convex response to sales growth shocks. In column (5) we introduce $\log$ Tobin's Q to our regression to capture the potential investment opportunities. In column (6) we run the regression with all control variables and our results are robust.

To quantify the effects, we focus on column (3) and compute the effect of a one standard deviation shocks for delay and caution effects. A one standard deviation increase in CRUX will result in a $1 \log$ point $(=-0.300 \times 0.033 \times 100)$ decrease in the corporate investment rate. The coefficient of the interaction term reflects the second order cautionary effect. Firms with high uncertainty would reduce investment rate even when they face high demand growth (sales growth). This caution effect is also reasonably large. A one standard deviation shock to sales would increase investment by about $4.6 \log$ points $(=0.078 \times 0.595 \times 100)$. But if CRUX was one standard deviation above its mean, e.g. $0.076=0.043+.033$, the investment response would be attenuated by $2.2 \log$ points $(=-0.494 \times 0.076 \times 0.595 \times 100)$, which is nearly half. 


\subsection{Establishment Level Manufacturing Investment}

Next we turn to our detailed data on establishment level manufacturing investment. We show that CRUX has a negative effect on uncertainty and quantify the impact.

The summary statistics for the ASM/CM sample appear in Table 4. We have roughly the same mean of 0.0409 for the CRUX measure as in the corporate investment sample. There are more observations relative to the COMPUSTAT sample because these are establishment level data, but fewer firms overall because all non-manufacturing firms are dropped 12

Starting in Table 5 with the rate of total investment, the sum of equipment and structures, we find a strong first order delay effect in columns 1-3 even after we control for sales growth (measured as the change in total value of establishment shipments) and industry-year fixed effects. In column (4) we add a demeaned interaction of sales growth with CRUX. The coefficient on sales growth alone is positive, but it's interaction with CRUX is negative and significant, as we predicted if caution effects were present. We add controls for firm-level Tobin's Q and the square of sales growth in columns (5) and (6). These variables are significant, but don't affect coefficients on the CRUX measure even when we include all of them together in column (7).

In Section 3.1 we noted caution effects were important evidence that CRUX was not simply of proxy for first moment shocks. We have already shown the caution effect is robust to inclusion of a battery of controls and fixed effects for unobservable firm and industry shocks. We go one step further in columns (8) and (9) by taking advantage of the establishment level variation in investment rates by adding a firmid-year fixed effect. This controls for all firm specific shocks to supply, demand, and the firm component of any unobserved first and second moment shocks, such as a firm's changing tone towards corporate reports and introduction of new mandatory sections to 10-K filings (e.g. the phase-in of Item 1A Risk Factors after 2006). Both the CRUX measure and any firm-specific controls like Tobin's Q are not identified. But because we have establishment level sales growth measures we can identify the investment effect of sales growth and its interaction with the firm-level CRUX measure.

In column (8), we see that the caution effect coefficient remains negative and significant and the coefficient on sales growth is positive. The magnitudes of identified coefficients are nearly

\footnotetext{
${ }^{12}$ Exact breakdowns across the samples cannot be provided due disclosure requirements. We provide propensity score weighted regressions in the robustness checks.
} 
unchanged in the saturated regression and robust to including the square of sales growth in column (9). These results strongly suggest that CRUX captures meaningful variation in uncertainty for the average firm. Moreover, the stability of our caution effect coefficients to the inclusion of firmid-year effects suggests that we have already adequately controlled for potential endogenous feedback of firm performance to CRUX in the less saturated baseline specification.

We repeat these specifications in Table 6, breaking out equipment and structures investment separately to better understand the mechanism through which uncertainty impacts investment. The delay effect is primarily driven by equipment investment as seen in the left hand panel. There is a negative effect on structures, but it is not significant. The latter may be due to the slower moving nature of investment in structures. For example, commitments to remodel a plant or repair a roof may respond more to long-run, persistent uncertainty. Whereas machine replacement or re-tooling can be more easily delayed. Nevertheless, the caution effects are negative and significant for both types of investment and robust in columns (3) and (6) to the inclusion of firm-year fixed effects 13

To visualize the effects of uncertainty, we take the coefficients from Table 5 , column (6) and plot establishment investment rate response to log sales growth under uncertainty the top panel of Figure 3. Each curve plots the investment response at the 5th, 25th, 50th, 75th and 95th percentile of our CRUX measure ${ }^{14}$ As uncertainty increases, the response curve shifts downward - a delay effect - and the slope of the curve flattens out - a caution effect. When CRUX is one SD above its mean (0.07), the investment rate is reduced by about $0.5 \log$ points $(=-0.068 \times 0.07 \times 100)$. At more than half the average rate in sample (0.818), this is economically significant. The bottom panel of Figure 3 decomposes the effects of high uncertainty (one standard deviation above mean) into delay and caution effects. The delay effect is independent of sales growth and represented by a level shift in investment rates. The magnitude of the caution effect is increasing with respect to sales growth, which we show as a further rotation of the marginal effect in the figure. If CRUX is zero, a one SD shock to total shipment growth increases investment by $1.8 \log$ points $(=0.044 \times 0.4 \times 100)$. But if uncertainty is also high, that effect is attenuated by almost $0.9 \log$ points $(=-0.314 \times 0.07 \times$

\footnotetext{
${ }^{13} \mathrm{~A}$ full set of results showing this breakout across all controls is available on request.

${ }^{14}$ These percentiles are from EDGAR-COMPUSTAT matched sample including only manufacturing firms (2-digit NAICS code ranging from 31 to 33). We do not use Census-based sample percentiles in order to avoid Census disclosure restrictions.
} 
$0.4 \times 100)$. This reduces the response to the sales shock by around half and accounts for more than $64 \%$ of the total reduction in the investment rate under uncertainty.

Last, we put the effect on investment into sharper contrast by estimating an investment spike regression. It is well known that investment is lumpy. New investment can be small to zero at many establishment and might only cover depreciation in many years (cf. Cooper and Haltiwanger, 2006). To capture lumpiness, we create a binary indicator for investment spikes that equals 1 if

the arithmetic investment rate is higher than $20 \%\left(\frac{I_{i t}}{K_{i t-1}} \geq 20 \%\right)$. We estimate a linear probability model with the indicator as the dependent variable and the same set of RHS variables and controls as our continuous baseline regressions. The results in Table 7 show strong evidence of both delay and caution effects that are robust to our full set of baseline controls in column (2) and firmid-year effects in column (3). Taking a CRUX shock that is $1 \mathrm{SD}$ above the mean again, we find the probability of an investment spike declines by almost 1 percent (about $20 \%$ below the sample mean spike rate of 5 percent). Moreover, the caution effect also reduces the probability of an investment spike following a sales shock from 1.6 percent under no uncertainty to 0.8 percent when CRUX is high.

In sum, when firms use uncertainty related words in public disclosures their investment behavior is fully consistent with models of investment under uncertainty. The evidence suggests a robust and economically significant link between high uncertainty measured by CRUX and the firm and establishment level investment response. A battery of further robustness tests appears in section 3.7. but next we investigate the impact on jobs and industry spillovers.

\subsection{Uncertainty mechanism for other within firm adjustment margins}

Having validated our uncertainty measure with well-defined capital investment measures, we now broaden our scope other margins that should respond similarly to uncertainty.

Data aggregated to the firm-level, such as COMPUSTAT, do not permit measurement or estimation of within firm margins of adjustment such as plant openings and and closing. Likewise, specific hiring and firing decisions are difficult to estimate without detailed data on labor adjustment costs, search and matching frictions, and regulations. Our approach exploits establishment dynamics within firms and across job creation and destruction margins. The LBD data allow us to track growth at continuing establishments as well as births, deaths, acquisitions, divestitures. 
Observing the birth or acquisition of new establishments within the firm, for example, is a form of investment activity. Likewise, death (closure) or divestiture of establishments is a form of disinvestment. We will estimate how these margins respond to changes in CRUX. Summary statistics for the regressions below appear in Appendix Table A1

Initially, we estimate the response of the extensive margin growth in the number of operating establishments to uncertainty. In Table 8, we use the same set of controls from our baseline results on investment. Firms' establishment and employment growth rates are calculated as DHS or midpoint growth rates: $\Delta y_{i t}=\left(y_{i t}-y_{i t-1}\right) /\left(0.5 \times\left(y_{i t}+y_{i t-1}\right)\right)$, where $y_{i t}$ is the number of establishments or total employment.15 This sample includes all industries, not just manufacturing, and these are within firm dynamics so we control for firm fixed effects and industry-year fixed effects. In the first column we find a negative, imprecisely estimated effect of CRUX on growth in the number of establishments. We find a positive effect of sales growth that is attenuated, significantly, when uncertainty is high. This negative caution effect prevails when controlling for Tobin's Q and squared sales growth in the remaining columns. More importantly, we continue to find delay and caution effects when adding the interaction of CRUX with lagged sales growth. The caution effect is robust to inclusion of Tobin's Q and squared sales growth in the remaining columns.

We then decompose growth into births, deaths, acquisition and divestiture margins that demonstrate "wait and see" dynamics consistent with our measure capturing firm uncertainty. If our CRUX measure was substantially contaminated by negative first moment shocks, then it would move the new investment and disinvestment margins in the same direction. We find the opposite is true. In Table 9, each coefficient in columns (2)-(5) can be summed to equal the net growth coefficient in column (1). In contrast to the weaker net response, we see that births (column 2) and acquisitions (column 4) contribute negatively and significantly to a reduction in net establishment growth through both a caution and delay effect. We also find no significant contribution from establishment deaths, which suggests uncertainty doesn't affect shutdown decisions for the average firm. Moreover, we find a positive and significant effect of uncertainty for the divestiture margin (divestiture enters with a negative sign so a positive coefficient implies a reduction in divestitures).

\footnotetext{
${ }^{15}$ This growth rate is symmetric, bounded on $[-2,2]$, equivalent to log changes up to a second order Taylor approximation, and allows us to additively decompose growth into margins.
} 
Taken together, a reduction in new investment activity (fewer births and acquisitions) and small to positive effects on disinvestment (deaths and divestiture) is strongly suggestive of "wait and see" dynamics: the inaction band in a canonical investment model have has widened.

Next, we estimate the employment growth implications across these establishment level adjustment margins. Starting with net firm employment growth in Table 10, we step through the same set of controls we used in the investment results. In the first column we find a negative and precisely estimated effect of CRUX on employment growth when controlling for firm fixed effects and industry-year fixed effects. We continue to find delay and caution effects when adding lagged sales growth (column 2) and the interaction of CRUX with lagged sales growth (column 3). The magnitudes of these effects on employment growth are large on average. When CRUX is one SD above its mean (0.07) employment growth falls by $1.4 \log$ points $(=-0.202 \times 0.07 \times 100)$. If there is a one SD sales growth shock, employment grows by $5.7 \log$ points when CRUX $=0$. But when uncertainty is also high, that employment growth is attenuated by $30 \%$, or $1.5 \log$ points $(=-0.560 \times 0.07 \times 37)$. The results are robust to inclusion of Tobin's Q, squared sales growth, and all controls together in columns 4-6.

We decompose employment growth into margins and estimate our baseline with CRUX, sales growth, their interaction, and a full set of firm and industry-year fixed effects in Table $11^{16}$ About $3 / 4$ of the estimated negative effect of uncertainty flows from reductions in job creation in establishment births and acquisitions; the latter are jobs-based measures of foregone investment opportunities. To corroborate this, we also find the divestiture margin has a positive sign, indicating fewer job losses through this margin. The effect on job destruction through establishment death (shutdowns) is negative, but imprecisely different from zero. Moreover, the response of gross job destruction (with or without divestitures)is not significantly different from zero 17 As with establishment growth rates, the muted response on the job destruction margins remains consistent with "wait and see" dynamics. A firm is less likely to disinvest in an ongoing operations when uncertainty is high.

\footnotetext{
${ }^{16}$ The highlighted results are robust to the full set of controls in Table 10 but omitted for brevity.

${ }^{17}$ Results grouping gross job creation and destruction margins together appear in Appendix Table A3.
} 


\subsection{Common Shocks and Industry Aggregation}

This section addresses several related questions about external validity and aggregation. Our goal is to estimate whether there there is a common industry component to the CRUX measure that can be captured through industry aggregation and whether it drives our results. We address this across several samples and collect the results here.

Our estimated effects may average together heterogeneous responses to aggregate uncertainty with heterogeneity in firm-specific uncertainty. Even if our results were driven entirely by heterogeneous responses to common shocks, they would still be interesting. But as we noted in section 3.1. under the identifying assumption that firms respond homogeneously to common shocks our time and industry-time dummy variables absorb them. Thus, we identify an average partial effect to firm-specific components of uncertainty.

If most of the uncertainty derives from a common industry component, then heterogeneity in text mentions and firm responses could drive our results. Our rich microdata variation in both the CRUX measure (see Table 1) and our outcome measures allow us to investigate this further and rule out a story driven entirely by common aggregate or industry shocks. To see this, we write firm-level uncertainty $\sigma_{i t}=\sigma_{t}^{A}+\tilde{\sigma}_{i t}$ as the sum of aggregate uncertainty, $\sigma_{t}^{A}$, and firm-level deviations from the aggregate, $\tilde{\sigma}_{i t}=\sigma_{i t}-\sigma_{t}^{A}$, as in section 3.1. A simplified regression equation with these elements is $\Delta y_{i t}=\left(\lambda_{i}^{A}-\tilde{\lambda}_{i}\right) \sigma_{t}^{A}+\tilde{\lambda}_{i} \sigma_{i t}+$ controls. If $\tilde{\lambda}_{i} \approx 0$ and $E\left(\lambda_{i}^{A}\right)<0$, then the negative effect of uncertainty follows from heterogeneity in the response to aggregate uncertainty.

At the other extreme, suppose $\lambda_{i}^{A}=\lambda^{A}$ and all firms respond the same the aggregate shocks. In this case the common shock response is absorbed by time dummies and $\lambda=E\left(\tilde{\lambda}_{i}\right)$ identified from the firm response to its own uncertainty.

In the rest of this section, we address the relative importance of each component in two ways. First, we include industry-time aggregated measures of CRUX as controls for industry aggregate uncertainty. Second, we allow for firm-specific heterogeneous slope coefficients on the the time and industry-time means of the CRUX measure within sample. 


\subsubsection{Industry Aggregation and Spillovers}

We construct a "Peer" CRUX to measure the industry uncertainty within the LBD manufacturing sample. First, we demean our CRUX measure at the firm-level to remove the time invariant, firm specific component. We denote this by $\widetilde{C R U X}_{j}$. Second, for each establishment $i$, the Peer CRUX is the simple average of the demeaned CRUX of all other establishments, not $i$, with operations in the same NAICS 4 digit industry $J$. Specifically, for each establishment $i \in J$ we compute

$$
\text { Peer } \operatorname{CRUX}_{i}=\frac{1}{J-1} \sum_{j \in J \backslash\{i\}} \widetilde{C R U X_{j}}
$$

Because we leave the establishment's own CRUX measure out of the industry index mean, we can still identify the effect even after we include industry-year fixed effects. Moreover, by adding this measure to our baseline regression, we can check whether the investment response to own CRUX is sensitive to including the corresponding industry measure.

In Table 12, we find a firm's own CRUX measure remains robustly negative and significant when we control for Peer CRUX measures. The sample is the same set of establishments that appear in the manufacturing investment baseline. Column (1) includes only the peer measure, where we find both caution and delay effects. In column (2), we add the firm-level CRUX and find both firm and peer caution and delay effects are negative and significant. Moreover, we can compare magnitudes directly if we normalize the estimated Peer CRUX coefficients to be in the same standard deviation units as the own CRUX measure. Using column (2) for example, we normalize the Peer CRUX coefficient by multiplying by it SD and dividing by the firm-level CRUX SD to obtain $-0.116=-0.268 \times(0.0125 / 0.0288)$, which is not much higher than the CRUX coefficient of -0.077 . Thus, the baseline CRUX measure includes firm-specific variation that is quantitatively robust to including a measure of a common, industry uncertainty shocks. Results are robust to adding additional controls in columns (3-4), or when identifying only the caution effect after including firm-year fixed effects in columns (5-6) 18

We have ruled out that our firm-level measure is only capturing industry level uncertainty shocks, but the within sample evidence suggests the firm CRUX does contain industry specific

\footnotetext{
${ }^{18}$ We also compute an industry CRUX measure by taking the propensity score weighted average of CRUX of all firms within the same industry (4-digit NAICS) given that we do not observe CRUX for non-public firms. Results are nearly the same and available on request.
} 
variation in uncertainty. So we construct an industry level CRUX measure by taking the average firm demeaned CRUX of all establishments within the same industry (4-digit NAICS). We can then estimate effects of industry level uncertainty on all establishments in U.S. manufacturing sector from the Census data.19

In Table 13, we regress the establishment total investment rate on the mean industry CRUX. ${ }^{20}$ We find strong effects on both delay and caution, and the coefficients barely change no matter how we weight the measure. The magnitude of the effects are sizable. Taking the coefficients from column (1), a one SD shock to industry CRUX (=0.0126) reduces the investment rate by $0.23 \log$ points $(=-0.184 \times 0.0126 \times 100)$, or about one-third of the average rate in the full manufacturing sample (0.654). If CRUX is zero, a one SD shock to total shipments growth increases investment by about $1 \log$ point $(=0.0230 \times 0.417 \times 100)$. But if uncertainty is also high, that effect is reduced by $0.2 \log$ points $(=-0.370 \times 0.0126 \times 0.417 \times 100)$, which attenuates the response by about $20 \%$. We find similar results when breaking out equipment and structures in Appendix Table A5.

\subsubsection{Heterogeneity of Response to Common Shocks}

We next allow for heterogeneous coefficients on CRUX yearly and industry-yearly means on the COMPUSTAT sample and show the estimated coefficient on the firm's own CRUX measure is robust.

The approach is as follows. Using the COMPUSTAT corporate investment sample, we demean the CRUX measure by firm $i$. We then take the simple average by year, $\overline{\mathrm{CRUX}}_{t}$, or industry-year, $\overline{\mathrm{CRUX}}_{I, t}$. We add these means to the regression, but because we already include industry-year effects, coefficients on these measures would not normally be identified. However, we allow for heterogeneous coefficients on these measures that vary by each firm $i$. For the annual average

\footnotetext{
${ }^{19}$ Summary statistics are in Appendix Table A4

${ }^{20}$ We also use a propensity score weighted mean and results are nearly identical. See robustness section 3.7 and the appendix for details on our propensity score estimates.
} 
$\overline{\mathrm{CRUX}}_{t}$, the regression equation is

$$
\begin{aligned}
\Delta y_{i t}= & \lambda \operatorname{CRUX}_{i t}+\eta \operatorname{CRUX}_{i t} \cdot \Delta \log (\text { sales })_{i t-1}+\beta^{\text {sales }} \Delta \log (\text { sales })_{i t-1} \\
& +\left(\lambda_{i}^{A}-\tilde{\lambda}_{i}\right) \times \overline{\operatorname{CRUX}}_{t}+\eta_{i}^{A} \times \operatorname{CRUX}_{i t} \cdot \Delta \log (\text { sales })_{i t-1} \\
& +\boldsymbol{\beta} \cdot \boldsymbol{X}_{i t-\mathbf{1}}+\alpha_{i}+\alpha_{t}+\epsilon_{i t} .
\end{aligned}
$$

We thus estimate a firm-specific slope coefficient to aggregate or industry uncertainty. If most of the investment delay and caution effects reflect a heterogeneous response of firms to common shocks, then adding these controls should attenuate the coefficients in the baseline regressions.

When compared to our baseline regression, we find no reduction in magnitudes from adding firm-specific slope to aggregates shocks for the caution or delay effects. In Table 14, we repeat our baseline in column (1). Column (2) adds the firm-specific controls in the second line of (3) on an aggregated CRUX measure. We don't report the coefficients as there are thousands of them. Their inclusion does not attenuate the baseline effects firms' own CRUX measure. Moreover, we cannot reject equality of the caution and delay coefficients on the firm's between the specifications. When we add industry-time aggregated CRUX measures in column (3), we find the same result.

\subsection{Robustness and Alternative Measures}

Our identification of both caution and delay effects across a rich set of fixed effects already indicate that our estimates are robust to unobserved industry- and firm-time varying factors that would bias our results. Nevertheless, we perform several robustness checks. For most of these checks, we primarily use the COMPUSTAT-based corporate investment sample to avoid disclosure of multiple Census subsamples. In what follows, we describe a number of robustness checks on alternative measures and some sample adjustments.

- Measurement Error in CRUX. To address the measurement error in CRUX, we define a binary indicator equal to 1 when CRUX is above the sample median and zero otherwise. Appendix Table A6 reports regression results of high vs. low CRUX measure on corporate investment

with same specification as the continuous CRUX measure. The results are robust to our baseline. 
- Using "Risk"-Related Word Index. We construct an alternative text based measure the same way we construct CRUX by exploiting "risk"-related words in EDGAR filings. The word list includes the words risk, risked, riskier, riskiest, riskily, riskiness, risking, risks, risky. In Appendix Table A7, we find such "risk"-related measure has a positive effect first-order effect on the investment rate and negative effect on second order interactions with sales growth. This suggests that "risk"-words may not be used in the context of uncertainty or second moment shocks in SEC filings. One explanation is that the use of the word "risk" does not describe business conditions, forecasts, etc.. For example, an insurance company may describe managing risk as a business line. Another firm may describe taking on risk or the "upside risk" of a project. These usages are either asymmetric or lead to noise in the measure. Another reason is that while economists have assigned distinct but related meaning to risk and uncertainty, usage in business reporting need not respect those definitions.

- Alternative Market Based Measure: Realized Volatility. We compute realized volatility by taking standard deviation of firms' monthly stock returns at year $t-1$. In Appendix Table A8, we control for realized volatility in our baseline regression. The CRUX measure coefficient signs and magnitudes are robust, suggesting it captures additional uncertainty factors not present in backward-looking, realized volatility measure. Realized volatility has a negative first order effect on corporate investment rate, but no caution effect.

- Alternative Market Based Measure: Implied Volatility. In Appendix Table A9, we control for implied volatility in our baseline CRUX regression on corporate investment.21 The CRUX measure is robust when controlling for implied volatility and explanatory power of implied volatility is weak. Another limitation of using implied volatility as an uncertainty measure is that it reduces the sample size by almost two thirds since only a small set of publicly traded firms have exchange traded options. That latter highlights another advantage of our measure: it can be computed for all public firms regardless of market capitalization or trading volume.

- Alternative Investment Measures. We have already shown our results hold for COMPUSTAT corporate investment (log changes), manufacturing investment in equipment and structures, and manufacturing investment spikes. We also check our main results using arithmetic invest-

\footnotetext{
${ }^{21}$ See Appendix for detailed construction.
} 
ment rates and logs of those rates using COMPUSTAT data. We normalize by alternative capital stock measures in year $t$ to confirm our results are not influenced by our capital price deflator, which is unlikely given we already absorb industry-year effects. In Appendix Table A10 we normalize capital expenditure by either gross property, plant and equipment in Panel A and firm's net gross property, plant and equipment in Panel B. Our results are robust. Note that when computing log of rates we are estimating the elasticity or semi-elasticity of the investment rate to changes in independent variables. Thus the interpretation of coefficient magnitudes, but not their sign, is different.

- Heterogeneity from introduction of "Item 1A: Risk Factors" requirement. The SEC required a risk factors (Item 1A) discussion in all reports from 2006 forward. This could have increased discussion of uncertainty (or risk) in company filings, but our data clearly show firms were mentioning risk and uncertainty regardless of SEC requirements before 2006. For some firms, the introduction of Item 1A may have spurred a simple reorganization of company reports. We have already shown the caution effect is robust to firmid-year fixed effect controls, which rules out this change driving our results. We also created a Risk Factors indicator variable equal to 1 if the firm reports text under the Item 1A Risk Factors section of their filings during the year and 0 otherwise. 22 We find no evidence of heterogeneity from a risk factors indicator on delay effects and some mild evidence for caution effects (Table A11 and A12) ${ }^{23}$

- Generalizations to non-public firms. Since the CRUX measure is only available for a set of publicly traded firms, results may not generalize to the set of all private sector employers. To handle this issue, we treat the LBD as the population universe of all firms and estimate propensity scores for publicly traded firms in our sample. We use the scores to inverse probability weight our regressions or construct aggregated CRUX measures. Our results are largely unchanged and we report them in the appendix for manufacturing investment (Appendix Tables A13) and the employment growth margins (Appendix Tables A14). This is likely because publicly traded firms tend to be larger than private firms in terms of sales and

\footnotetext{
${ }^{22}$ Even though SEC made Item 1A mandatory from 2006, not every firm reports it every year and not every firm started reporting it at the same time. This gives our indicator variable firm-year variation.

${ }^{23}$ The introduction of the Risk Factors section precedes the financial crisis and Great Recession, when uncertainty was high, which is another reason a Risk Factors indicator may be generating heterogeneity in the estimates. The more coarse post-2006 indicator applied to all firms regardless of the actual text in their reports suggests this is the case.
} 
employment and they contribute to a substantial share of aggregate output. So studying the uncertainty dynamics within publicly traded firms may be illuminating about firm behavior in the aggregate economy.

\section{Conclusion}

We construct a new time-varying measure of firm-specific uncertainty from analyzing the text of company reports filed with the U.S. Securities and Exchange Commission. We explore the implications of variation in firm-level uncertainty for investment, employment and firm dynamics.

We find that firm-specific uncertainty has large, negative effects on broad set of investment activity: capital equipment and structures, corporate investment, plant or establishment openings, and job creation margins. Our results are not driven by common aggregate and industry uncertainty shocks. For manufacturing, the negative effects are largest on equipment relative to structures and we also find firm uncertainty substantially reduces investment spikes. Most of the response within firms occurs on the establishment birth, acquisition, and gross job creation margins, primarily through reductions in employment growth from the new establishments, acquisitions, and continuer margins. The effects on establishment death, divestiture, and gross job destruction are smaller and less precisely estimated. Taken together these results are consistent with an $(\mathrm{s}, \mathrm{S})$ model of investment where uncertainty increases the hurdle rate for new investment, new plants and lowers the threshold that induces disinvestment, plant shutdowns, and job destruction.

We also find strong cautionary effects for investment in the face of high uncertainty that have broader implications. The investment response to good demand shocks is attenuated by up to $50 \%$ when accompanied by a high uncertainty shock. Thus, cautionary effects may help explain the sluggish recovery from some downturns. Even if fundamentals or expectations improve, e.g. sales growth or fiscal and monetary policy interventions, our evidence suggests investment will not recover quickly when firms' own uncertainty remains high. Recent evidence also finds that weaker firm-level responsiveness to shocks has contributed to declines in productivity enhancing reallocation and business dynamism (Decker et al., Forth.). So periods of high uncertainty for specific firms or industries may have longer run effects on firm performance and economic growth. 


\section{References}

Abel, Andrew B and Janice C Eberly. 1994. "A Unified Model of Investment under Uncertainty." American Economic Review 84 (5):1369-1384.

Avramov, Doron, Minwen Li, and Hao Wang. 2016. "Risk and Corporate Policies: A Text-Based Analysis." Available at SSRN 2732564 .

Bachmann, Rüdiger and Christian Bayer. 2013. "Wait-and-See' business cycles?" Journal of Monetary Economics 60 (6):704-719.

- 2014. "Investment Dispersion and the Business Cycle." American Economic Review 104 (4):1392-1416.

Bachmann, Rüdiger, Steffen Elstner, and Eric R. Sims. 2013. "Uncertainty and Economic Activity: Evidence from Business Survey Data." American Economic Journal: Macroeconomics 5 (2):217249.

Baker, Scott R., Nicholas Bloom, and Steven J. Davis. 2016. "Measuring Economic Policy Uncertainty." The Quarterly Journal of Economics 131 (4):1593-1636.

Barrero, Jose Maria, Nicholas Bloom, and Ian Wright. 2017. "Short and Long Run Uncertainty." NBER Working Papers 23676, National Bureau of Economic Research, Inc.

Ben-David, Itzhak and John R. Graham. 2013. "Managerial Miscalibration.” The Quarterly Journal of Economics 128 (4):1547-1584.

Bernanke, Ben S. 1983. "Irreversibility, Uncertainty, and Cyclical Investment." The Quarterly Journal of Economics 98 (1):85-106.

Bloom, Nicholas. 2009. "The Impact of Uncertainty Shocks." Econometrica 77 (3):623-685.

Bloom, Nicholas, Steven J. Davis, Lucia Foster, Brian Lucking, Scott Ohlmacher, and Itay Saporta Eksten. 2017. "Business-Level Expectations and Uncertainty." Available at SSRN 3085377.

Bloom, Nicholas, Max Floetotto, Nir Jaimovich, Itay Saportaâ€ Eksten, and Stephen J. Terry. 2018. "Really Uncertain Business Cycles." Econometrica 86 (3):1031-1065.

Bloom, Nick, Stephen Bond, and John Van Reenen. 2007. "Uncertainty and Investment Dynamics." Review of Economic Studies 74 (2):391-415.

Bodnaruk, Andriy, Tim Loughran, and Bill McDonald. 2015. "Using 10-K Text to Gauge Financial Constraints." Journal of Financial and Quantitative Analysis 50 (4):623-646.

Buehlmaier, Matthias M M and Toni M Whited. 2018. "Are Financial Constraints Priced? Evidence from Textual Analysis." Review of Financial Studies 31 (7):2693-2728.

Cattaneo, Matias D., Richard K. Crump, Max H. Farrell, and Yingjie Feng. 2019. "On Binscatter." Papers 1902.09608, arXiv.org.

Cooper, Russell W. and John C. Haltiwanger. 2006. "On the Nature of Capital Adjustment Costs." The Review of Economic Studies 73 (3):611-633. 
Davis, Steven J., John Haltiwanger, Kyle Handley, Ron Jarmin, Josh Lerner, and Javier Miranda. 2014. "Private Equity, Jobs, and Productivity." American Economic Review 104 (12):3956-3990.

Decker, Ryan A., John Haltiwanger, Ron S. Jarmin, and Javier Miranda. Forthcoming. "Changing Business Dynamism and Productivity: Shocks versus Responsiveness." American Economic Review .

Dixit, Avinash K. 1989. "Entry and Exit Decisions under Uncertainty." Journal of Political Economy 97 (3):620-638.

Fort, Teresa C. and Shawn D. Klimek. 2018. "The Effects of Industry Classification Changes on US Employment Composition." Working Papers 18-28, Center for Economic Studies, U.S. Census Bureau.

Foster, Lucia, Cheryl Grim, and John Haltiwanger. 2016. "Reallocation in the Great Recession: Cleansing or Not?" Journal of Labor Economics 34 (S1):293-331.

Gabaix, Xavier. 2011. "The Granular Origins of Aggregate Fluctuations." Econometrica 79 (3):733772 .

Guiso, Luigi and Giuseppe Parigi. 1999. "Investment and Demand Uncertainty." The Quarterly Journal of Economics 114 (1):185-227.

Handley, Kyle. 2014. "Exporting under trade policy uncertainty: Theory and evidence." Journal of International Economics 94 (1):50-66.

Handley, Kyle and Nuno Limão. 2017. "Policy Uncertainty, Trade, and Welfare: Theory and Evidence for China and the United States." American Economic Review 107 (9):2731-83.

Hansen, Stephen, Michael McMahon, and Andrea Prat. 2018. "Transparency and Deliberation Within the FOMC: A Computational Linguistics Approach." The Quarterly Journal of Economics 133 (2):801-870.

Hassan, Tarek A, Stephan Hollander, Laurence van Lent, and Ahmed Tahoun. 2019. "Firm-Level Political Risk: Measurement and Effects." The Quarterly Journal of Economics 134 (4):21352202 .

Hoberg, Gerard and Gordon Phillips. 2016. "Text-Based Network Industries and Endogenous Product Differentiation." Journal of Political Economy 124 (5):1423-1465.

Jurado, Kyle, Sydney C. Ludvigson, and Serena Ng. 2015. "Measuring Uncertainty." American Economic Review 105 (3):1177-1216.

Kahneman, Daniel. 2003. "Maps of Bounded Rationality: Psychology for Behavioral Economics." American Economic Review 93 (5):1449-1475.

Keynes, J. M. 1937. "The General Theory of Employment." The Quarterly Journal of Economics $51(2): 209-223$.

Leahy, John V and Toni M Whited. 1996. "The Effect of Uncertainty on Investment: Some Stylized Facts." Journal of Money, Credit and Banking 28 (1):64-83.

Li, Feng. 2010. "Textual Analysis of Corporate Disclosures: A Survey of the Literature." Journal of Accounting Literature 29:143-165. 
Li, Feng, Russell Lundholm, and Michael Minnis. 2013. "A Measure of Competition Based on 10-K Filings." Journal of Accounting Research 51 (2):399-436.

Loughran, Tim and Bill Mcdonald. 2016. "Textual Analysis in Accounting and Finance: A Survey." Journal of Accounting Research 54 (4):1187-1230.

Morikawa, Masayuki. 2016. "Business uncertainty and investment: Evidence from Japanese companies." Journal of Macroeconomics 49 (C):224-236.

Novy, Dennis and Alan M. Taylor. Forthcoming. "Trade and Uncertainty." The Review of Economics and Statistics .

Schaal, Edouard. 2017. "Uncertainty and Unemployment." Econometrica 85 (6):1675-1721.

Sharpe, Steven A., Nitish R. Sinha, and Christopher A. Hollrah. 2017. "What's the Story? A New Perspective on the Value of Economic Forecasts." Finance and Economics Discussion Series 2017-107, Board of Governors of the Federal Reserve System (U.S.).

Shepotylo, Oleksandr and Jan Stuckatz. 2018. "Political Uncertainty, FDI, and Trade In Intermediate Goods: Evidence From Ukrainian Firms." Available at SSRN 2983695 .

Stein, Luke C.D. and Elizabeth Stone. 2013. "The Effect of Uncertainty on Investment, Hiring, and R\&D: Causal Evidence from Equity Options." Available at SSRN 1649108 . 


\section{Figures}

Figure 1: Investment vs. Firm Uncertainty

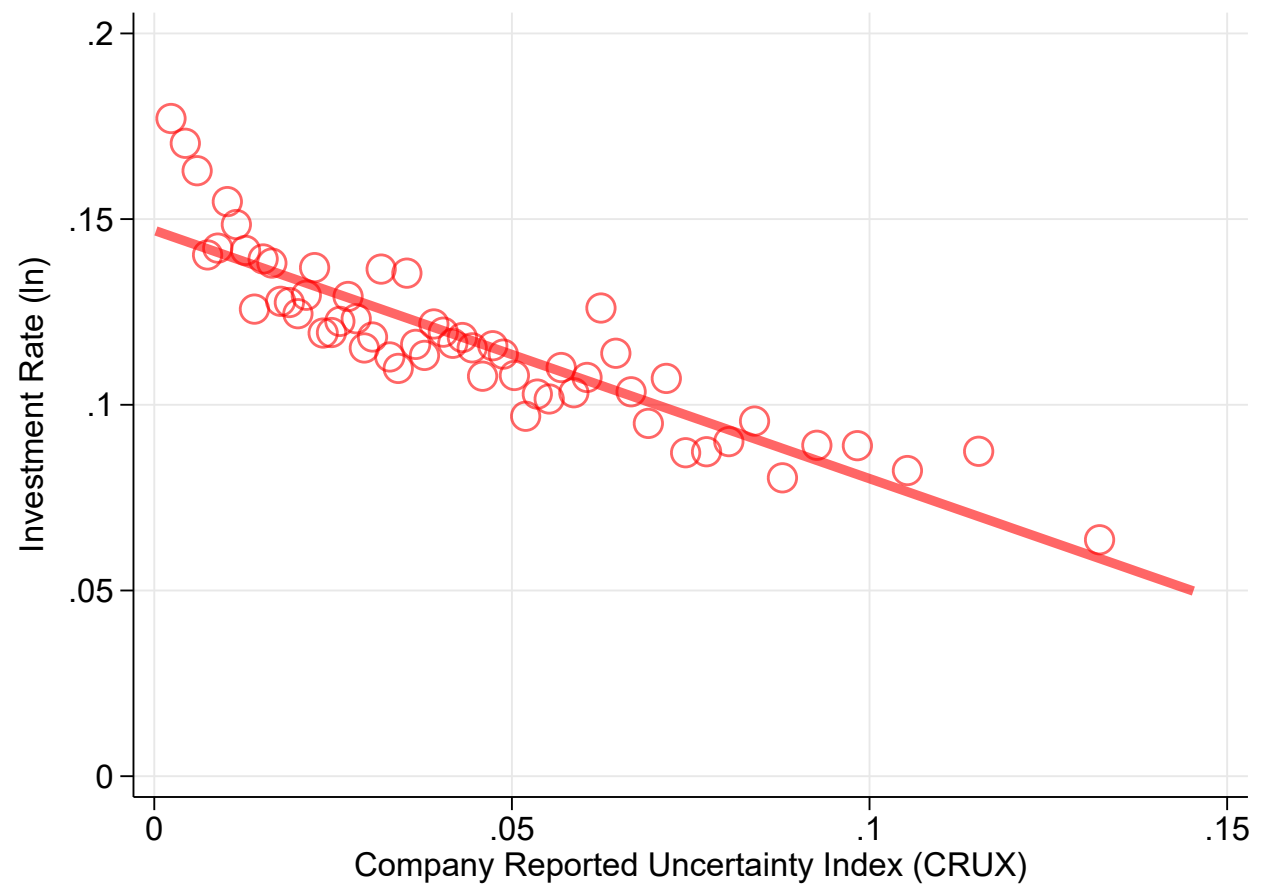

Notes: COMPUSTAT investment sample. Each circle is the mean investment rate within bins optimally selected following Cattaneo et al. (2019). Robust to partialling out controls for sales growth, Tobin's Q, and year indicators. 
Figure 2: Investment vs. Sales Growth for High and Low Uncertainty

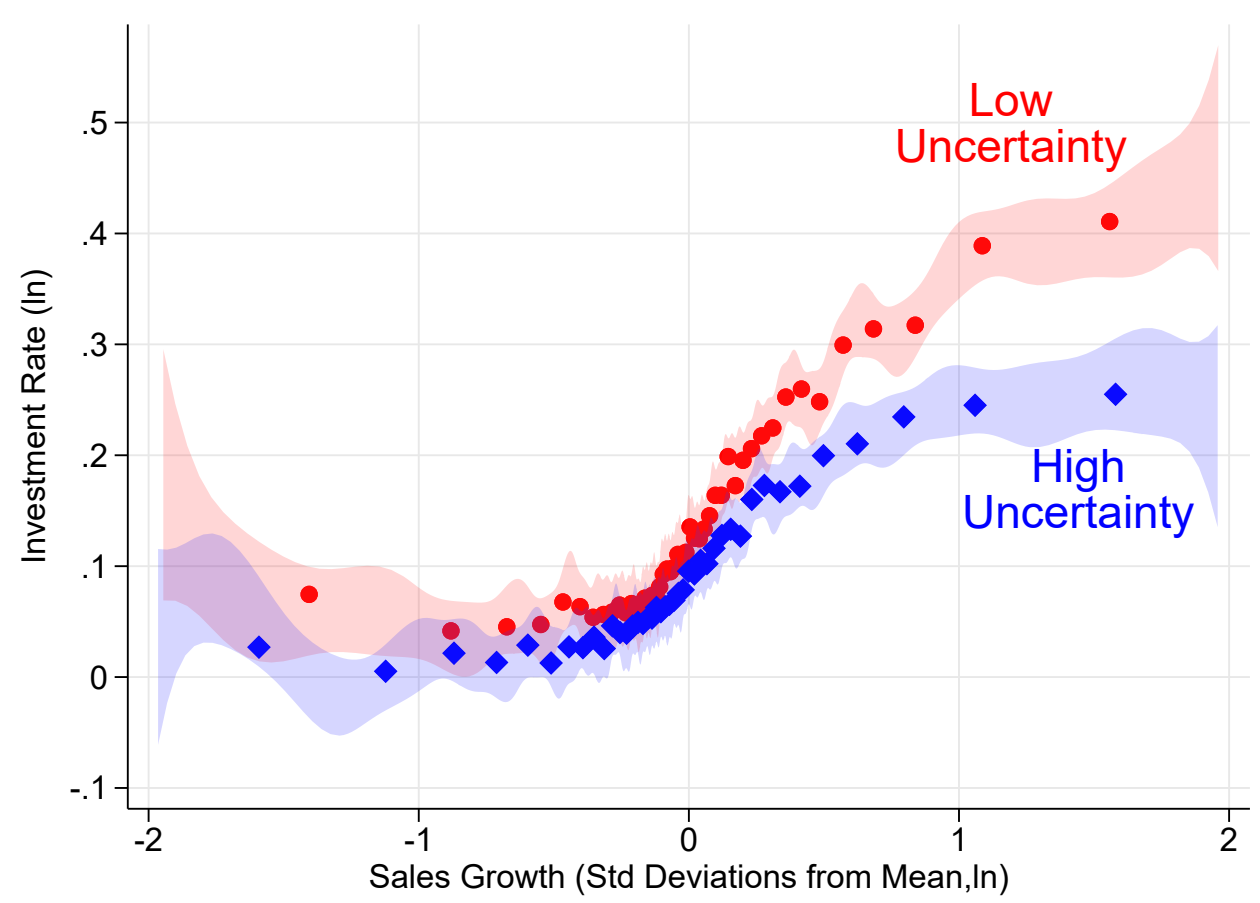

Notes: COMPUSTAT investment sample split into high uncertainty (top tercile of CRUX distribution) and low uncertainty (bottom tercile). Sales growth demeaned and normalized to standard deviation units. Each circle or diamond is the mean investment rate within the bin for sales growth. Shaded 95\% confidence intervals are smoothed cubic B-spline estimates over the data. Bins optimally selected and confidence interval selected following Cattaneo et al. (2019). Robust to partialling out controls for Tobin's Q and year indicators. 
Figure 3: Effect of Uncertainty on Manufacturing Investment Rate $(\Delta \ln )$

(a) Investment Response to Sales Shocks by CRUX percentile

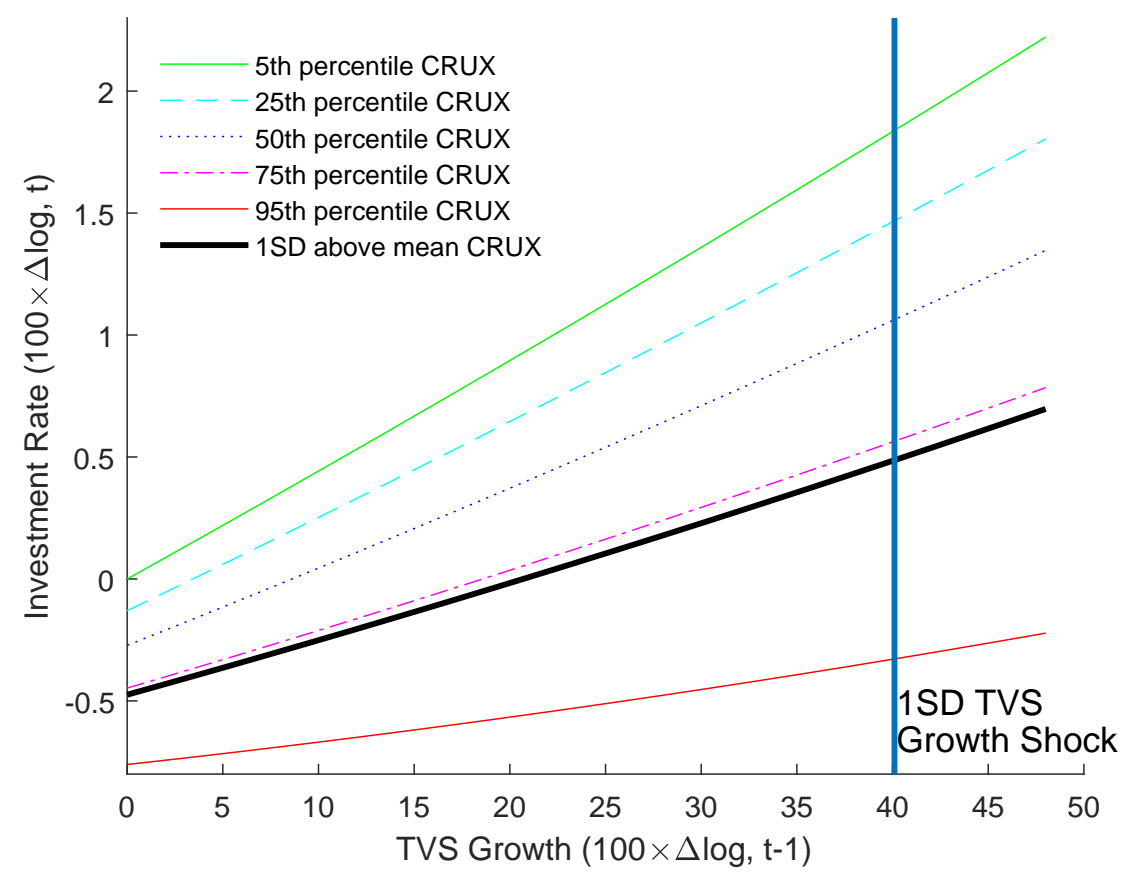

(b) Delay vs Caution Effect Decomposition

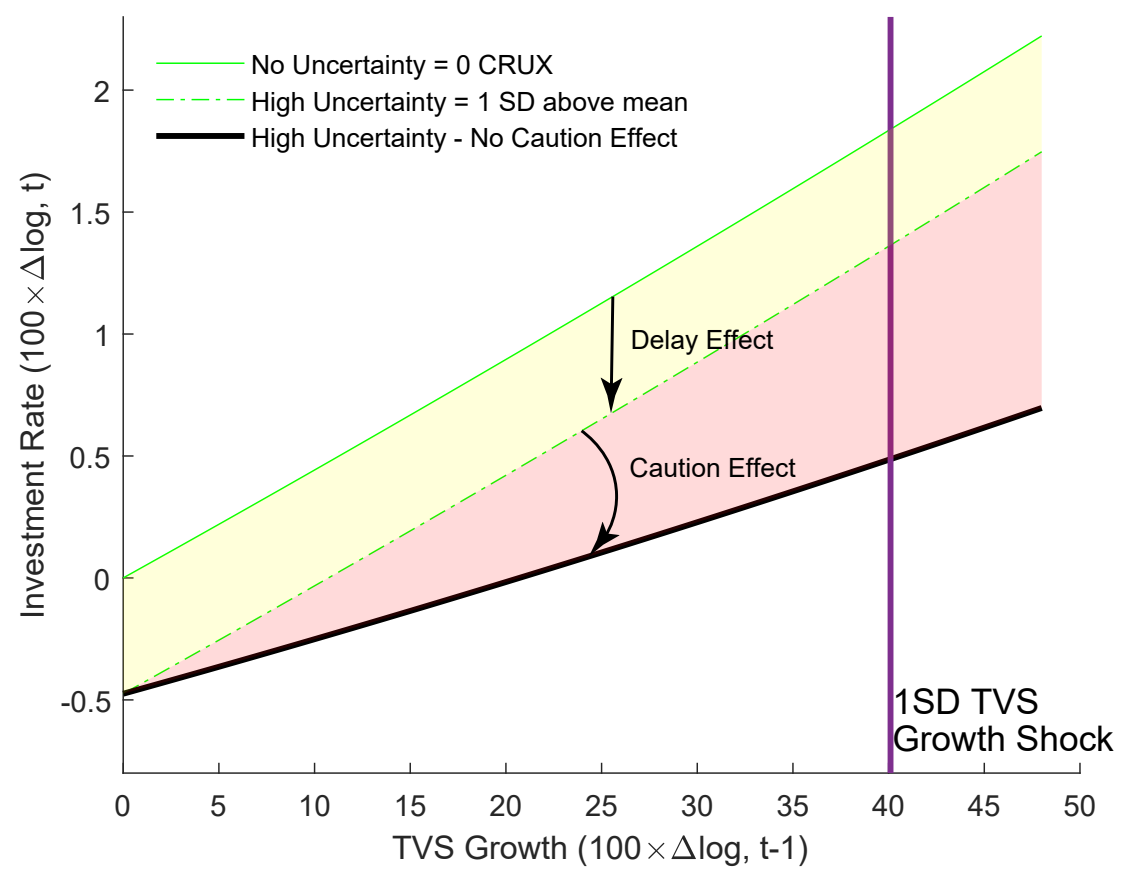

Notes: This figure presents establishment total investment growth's response function to log TVS growth under uncertainty according to column 6 from Table 5 . In Figure (a), we draw CRUX at 5th, 25th, 50th, 75th and 95th percentile from EDGAR-COMPUSTAT matched sample manufacturing firms (2-digit NAICS 31-33) as well as CRUX at one standard deviation above mean from EDGARCOMPUSTAT-CM/ASM matched sample. Figure (b) plots the decomposition of delay and caution effect when CRUX jumps from 0 to high (one standard deviation above mean). 


\section{Tables}

Table 1: Decomposition of Variance of CRUX

\begin{tabular}{lcc}
\hline & \multicolumn{2}{c}{ Compustat Corporate Investment Sample } \\
& $(1)$ & $(2)$ \\
& R-squared & Incremental R-squared \\
\hline Time FE & $20.67 \%$ & $20.67 \%$ \\
Industry FE (3-digit NAICS) & $4.69 \%$ & $4.27 \%$ \\
Industry (3-digit NAICS) $\times$ Time FE & $26.76 \%$ & $1.83 \%$ \\
Firm FE & $48.86 \%$ & $36.24 \%$ \\
Unexplained Residual & - & $37.00 \%$ \\
\hline & & \\
Number of Industries & 91 & 91 \\
Number of Firms & 10,445 & 10,445 \\
Number of Observations & 93,741 & 93,741 \\
\hline
\end{tabular}

Notes: This table reports variance decomposition of CRUX in Compustat corporate investment sample. Column (1) reports the R-squared values when regressing CRUX on each of the fixed effects alone. Column (2) reports the incremental addition to the R-squared values when regressing CRUX on additional fixed effects from previous row. Thus time invariant firm effects and industry $\times$ time effects explain $63 \%$ of the variation in CRUX. The share of unexplained residual variation is $37 \%$.

Table 2: Summary Statistics - Compustat Firm Level Data

\begin{tabular}{lcc}
\hline VARIABLES & Mean & Std Dev \\
\hline CRUX & 0.0429 & {$[0.0334]$} \\
Investment growth & 0.120 & {$[0.255]$} \\
Lag sales growth (log) & 0.114 & {$[0.595]$} \\
Lag Tobin's Q (log) & 0.589 & {$[0.759]$} \\
Lag sales growth (log) squared & 0.367 & {$[2.204]$} \\
\hline Number of Observations & 93,741 & \\
\hline
\end{tabular}


Table 3: Effects of Uncertainty on Corporate Investment Rate ( $\Delta \ln$, Compustat)

\begin{tabular}{|c|c|c|c|c|c|c|}
\hline \multirow[b]{2}{*}{ VARIABLES } & \multicolumn{6}{|c|}{ Dependent Variable: Log Change in Capital Stock K $(\Delta \ln , \mathrm{t})$} \\
\hline & (1) & $(2)$ & (3) & (4) & $(5)$ & (6) \\
\hline $\operatorname{CRUX}(\mathrm{t})$ & $\begin{array}{c}-0.349 * * * \\
{[0.0430]}\end{array}$ & $\begin{array}{c}-0.309 * * * \\
{[0.0430]}\end{array}$ & $\begin{array}{c}-0.300 * * * \\
{[0.0425]}\end{array}$ & $\begin{array}{c}-0.301 * * * \\
{[0.0424]}\end{array}$ & $\begin{array}{c}-0.298^{* * *} \\
{[0.0413]}\end{array}$ & $\begin{array}{c}-0.299 * * * \\
{[0.0412]}\end{array}$ \\
\hline Sales Growth $(\Delta \ln \mathrm{t}-1)$ & & & $\begin{array}{c}0.0775 * * * \\
{[0.00546]}\end{array}$ & $\begin{array}{c}0.0756 * * * \\
{[0.00533]}\end{array}$ & $\begin{array}{c}0.0712 * * * \\
{[0.00521]}\end{array}$ & $\begin{array}{c}0.0698 * * * \\
{[0.00511]}\end{array}$ \\
\hline CRUX $(\mathrm{t}) \times$ Sales Growth $(\Delta \ln \mathrm{t}-1)$ & & & $\begin{array}{c}-0.494^{* * *} \\
{[0.0705]}\end{array}$ & $\begin{array}{c}-0.480 * * * \\
{[0.0708]}\end{array}$ & $\begin{array}{c}-0.456 * * * \\
{[0.0686]}\end{array}$ & $\begin{array}{c}-0.445^{* * *} \\
{[0.0688]}\end{array}$ \\
\hline Sales Growth $(\Delta \ln \mathrm{t}-1)$ sqaured & & & & $\begin{array}{c}0.00299 * * * \\
{[0.000826]}\end{array}$ & & $\begin{array}{c}0.00229 * * * \\
{[0.000765]}\end{array}$ \\
\hline Log Tobin's Q (t-1) & & & & & $\begin{array}{c}0.0893 * * * \\
{[0.00338]}\end{array}$ & $\begin{array}{l}0.0890^{* * *} \\
{[0.00338]}\end{array}$ \\
\hline $\begin{array}{l}\text { Firm Fixed Effects } \\
\text { Year Fixed Effects }\end{array}$ & $v$ & $\checkmark$ & $v$ & 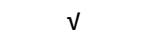 & $v$ & $\checkmark$ \\
\hline $\begin{array}{l}\text { Year Fixed Effects } \\
\text { Industry } \times \text { Year Fixed Effects }\end{array}$ & $\mathrm{v}$ & $\mathrm{v}$ & $v$ & $v$ & $\checkmark$ & $\checkmark$ \\
\hline Observations & 93,741 & 93,741 & 93,741 & 93,741 & 93,741 & 93,741 \\
\hline R-squared & 0.081 & 0.391 & 0.405 & 0.405 & 0.427 & 0.427 \\
\hline Number of Firms & 10,445 & 10,445 & 10,445 & 10,445 & 10,445 & 10,445 \\
\hline $\begin{array}{l}\text { Notes: Standard errors are cluster } \\
\text { stock. Firm uncertainty measure } \\
\text { calculated as } \log (\text { Sales }(\mathrm{t}-1))-\log \\
\text { growth. Tobin's } Q \text { is taken as } \log \\
\text { Column (2)-(6) include industry } \times \\
\text { compared with Column (1) due to } \\
* * * p<0.01, * * p<0.05, * p<0.1\end{array}$ & $\begin{array}{l}\text { at firm level. } \\
\mathrm{X} \text { is at time } \\
\text { es( }(\mathrm{t}-2)) \text { and } \\
\text { rage } \mathrm{Q} \text { at tim } \\
\mathrm{FE} \text {, where ir } \\
\text { leton observo }\end{array}$ & $\begin{array}{l}\text { endent varia } \\
\text { ch as mentic } \\
\text { aned by san } \\
\text { All of the } \\
\text { ry is at 3-dig } \\
\text { Time range }\end{array}$ & $\begin{array}{l}\text { s calculated } \\
\text { in the text } \\
\text { mean. Squa } \\
\text { ssion specif } \\
\text { AICS code le } \\
\text { m } 1994 \text { to } 2\end{array}$ & $\begin{array}{l}g(K(t))-\log ( \\
\text { ures firm und } \\
\text { sales growth } \\
\text { ons include fi } \\
\text { Column (2)-(6 }\end{array}$ & $\begin{array}{l}\text { ) where } \mathrm{K} \\
\text { nty at time } \\
\text { alculated } \mathrm{u} \\
\text { E. Column } \\
\text { s some ob }\end{array}$ & $\begin{array}{l}\text { 's total capita } \\
\text { Sales growth } \mathrm{i} \\
\text { demeand sale } \\
\text { cludes Year FE } \\
\text { tions and firm }\end{array}$ \\
\hline
\end{tabular}


Table 4: Summary Statistics - ASM/CM Establishment Level Data (Matched Sample)

\begin{tabular}{lcc}
\hline VARIABLES & Mean & Std Dev \\
\hline CRUX & 0.0409 & {$[0.0288]$} \\
Peer CRUX & 0.000804 & {$[0.0125]$} \\
Log Total Investment Rate & 0.00818 & {$[0.147]$} \\
Investment Spike & 0.047 & {$[0.212]$} \\
Log Structure Investment Rate & 0.00178 & {$[0.117]$} \\
Log Equipment Investment Rate & 0.0113 & {$[0.175]$} \\
Lag TVS growth (log) & 0.0094 & {$[0.401]$} \\
Lag TVS Growth (log) squared & 0.161 & {$[1.011]$} \\
Lag Tobin's Q (log) & 0.437 & {$[0.378]$} \\
\hline Number of Observations & 133,000 & \\
\hline
\end{tabular}


Table 5: Effect of Uncertainty on Manufacturing Establishment Level Total Investment Rate $(\Delta \ln )$

\begin{tabular}{|c|c|c|c|c|c|c|c|c|c|}
\hline \multirow[b]{2}{*}{ VARIABLES } & \multicolumn{9}{|c|}{ Dependent Variable: Log Total Investment Rate $(\Delta \ln , \mathrm{t})$} \\
\hline & $(1)$ & $(2)$ & (3) & (4) & (5) & (6) & (7) & (8) & (9) \\
\hline \multirow[t]{2}{*}{$\operatorname{CRUX}(\mathrm{t})$} & $-0.0670 * *$ & $-0.0662 *$ & $-0.0685^{*}$ & $-0.0690 *$ & $-0.0676 *$ & $-0.0681 *$ & $-0.0667^{*}$ & & \\
\hline & {$[0.0321]$} & {$[0.0355]$} & [0.0353] & {$[0.0353]$} & {$[0.0354]$} & [0.0354] & {$[0.0354]$} & & \\
\hline \multirow[t]{2}{*}{ TVS Growth ( $\Delta \ln \mathrm{t}-1)$} & & & $0.0327 * * *$ & $0.0460 * * *$ & $0.0458 * * *$ & $0.0437 * * *$ & $0.0435 * * *$ & $0.0470 * * *$ & $0.0448 * * *$ \\
\hline & & & {$[0.00375]$} & {$[0.00694]$} & {$[0.00697]$} & {$[0.00647]$} & {$[0.00650]$} & {$[0.00690]$} & {$[0.00642]$} \\
\hline \multirow[t]{2}{*}{ CRUX $(\mathrm{t}) \times$ TVS Growth $(\Delta \ln \mathrm{t}-1)$} & & & & $-0.335^{* * *}$ & $-0.337 * * *$ & $-0.314 * * *$ & $-0.316 * * *$ & $-0.373 * * *$ & $-0.354 * * *$ \\
\hline & & & & [0.114] & [0.114] & [0.110] & [0.110] & [0.121] & [0.118] \\
\hline \multirow[t]{2}{*}{ TVS Growth ( $\Delta \ln \mathrm{t}-1)$ squared } & & & & & & $0.00540 * * *$ & $0.00541 * * *$ & & $0.00492 * * *$ \\
\hline & & & & & & {$[0.00186]$} & {$[0.00186]$} & & {$[0.00190]$} \\
\hline \multirow[t]{2}{*}{ Log Tobin's Q (t-1) } & & & & & $0.0153^{* * *}$ & & $0.0154 * * *$ & & \\
\hline & & & & & {$[0.00322]$} & & {$[0.00320]$} & & \\
\hline Firm Fixed Effects & $v$ & v & v & v & $\mathrm{v}$ & $\mathrm{v}$ & $\mathrm{v}$ & & \\
\hline Firm $\times$ Year Fixed Effects & & & & & & & & 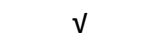 & $v$ \\
\hline Year Fixed Effects & $\mathrm{V}$ & & & & & & & & \\
\hline Industry $\times$ Year Fixed Effects & & $\mathrm{v}$ & $\sqrt{ }$ & $\mathrm{v}$ & $\mathrm{v}$ & $\mathrm{v}$ & $\mathrm{v}$ & $\mathrm{v}$ & $\mathrm{v}$ \\
\hline R-squared & 0.063 & 0.073 & 0.08 & 0.081 & 0.081 & 0.082 & 0.083 & 0.226 & 0.227 \\
\hline
\end{tabular}

Notes: Standard errors are clustered at firm level. Dependent variable is calculated as $\log (\mathrm{K}(\mathrm{t}))-\log (\mathrm{K}(\mathrm{t}-1))$ where $\mathrm{K}$ is establishment's total capital stock. Firm level uncertainty measure CRUX is at time $t$, which as mentioned in the text captures firm uncertainty at time t-1. Establishment level TVS (total value of shipment) growth is calculated as $\log ($ TVS(t-1)) - $\log ($ TVS(t-2)) and demeaned by sample mean. Squared TVS growth is calculated using demeand TVS growth. Firm level Tobin's $Q$ is taken as log average $Q$ at time t-1. Columns (1)-(7) include firm FE, Columns (8)-(9) include firm $\times$ year FE, which absorbs CRUX ( $t$ ) and Log Tobin's $Q$ (t-1). Column (1) includes Year FE, Columns (2)-(9) include industry $\times$ year FE, where industry is at 3-digit NAICS code level. Time ranges from 1998 to 2014 . Number of observations is 133000 and number of firms is 2000 , both rounded to the nearest thousands.

$* * * p<0.01, * * p<0.05, * p<0.1$ 
Table 6: Effect of Uncertainty on Equipment vs. Structure Investment Rate $(\Delta \ln )$

\begin{tabular}{|c|c|c|c|c|c|c|}
\hline \multirow[b]{2}{*}{ VARIABLES } & \multicolumn{3}{|c|}{ Log Equipment Investment Rate $(\Delta \ln , \mathrm{t})$} & \multicolumn{3}{|c|}{ Log Structure Investment Rate $(\Delta \ln , \mathrm{t})$} \\
\hline & $(1)$ & $(2)$ & (3) & $(4)$ & (5) & $(6)$ \\
\hline $\operatorname{CRUX}(\mathrm{t})$ & $\begin{array}{c}-0.0787^{*} \\
{[0.0437]}\end{array}$ & $\begin{array}{c}-0.0760^{*} \\
{[0.0441]}\end{array}$ & & $\begin{array}{c}-0.0284 \\
{[0.0252]}\end{array}$ & $\begin{array}{c}-0.027 \\
{[0.0251]}\end{array}$ & \\
\hline TVS Growth $(\Delta \ln \mathrm{t}-1)$ & $\begin{array}{c}0.0554 * * * \\
{[0.00808]}\end{array}$ & $\begin{array}{c}0.0527 * * * \\
{[0.00759]}\end{array}$ & $\begin{array}{c}0.0545 * * * \\
{[0.00737]}\end{array}$ & $\begin{array}{c}0.0254^{* * *} \\
{[0.00500]}\end{array}$ & $\begin{array}{c}0.0242 * * * \\
{[0.00471]}\end{array}$ & $\begin{array}{c}0.0246 * * * \\
{[0.00498]}\end{array}$ \\
\hline $\operatorname{CRUX}(\mathrm{t}) \times \operatorname{TVS}$ Growth $(\Delta \ln \mathrm{t}-1)$ & $\begin{array}{c}-0.378 * * * \\
{[0.136]}\end{array}$ & $\begin{array}{c}-0.358^{* * *} \\
{[0.132]}\end{array}$ & $\begin{array}{c}-0.408 * * * \\
{[0.138]}\end{array}$ & $\begin{array}{c}-0.205^{* *} \\
{[0.0823]}\end{array}$ & $\begin{array}{c}-0.197 * * \\
{[0.0791]}\end{array}$ & $\begin{array}{c}-0.196^{* *} \\
{[0.0903]}\end{array}$ \\
\hline TVS Growth ( $\Delta \ln \mathrm{t}-1)$ squared & & $\begin{array}{c}0.00566^{* * *} \\
{[0.00204]}\end{array}$ & $\begin{array}{c}0.00502 * * \\
{[0.00205]}\end{array}$ & & $\begin{array}{c}0.0025 \\
{[0.00157]}\end{array}$ & $\begin{array}{c}0.00221 \\
{[0.00165]}\end{array}$ \\
\hline Log Tobin's Q (t-1) & & $\begin{array}{c}0.0199 * * * \\
{[0.00416]}\end{array}$ & & & $\begin{array}{l}0.0113 * * * \\
{[0.00219]}\end{array}$ & \\
\hline Firm Fixed Effects & $v$ & v & & $v$ & 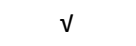 & \\
\hline Firm $\times$ Year Fixed Effects & & & v & & & v \\
\hline Industry $\times$ Year Fixed Effects & $\sqrt{ }$ & $\sqrt{ }$ & $\sqrt{ }$ & $v$ & $\mathrm{v}$ & 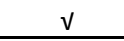 \\
\hline R-squared & 0.094 & 0.095 & 0.24 & 0.048 & 0.049 & 0.185 \\
\hline
\end{tabular}

Notes: Standard errors are clustered at firm level. Dependent variable is calculated as $\log (K(\mathrm{t}))-\log (\mathrm{K}(\mathrm{t}-1))$ where $\mathrm{K}$ is establishment's total capital stock in equipment or structure. Firm level uncertainty measure CRUX is at time $t$, which as mentioned in the text captures firm uncertainty at time $\mathrm{t}-1$. Establishment level TVS (total value of shipment) growth is calculated as $\log (\mathrm{TVS}(\mathrm{t}-1))-\log (\mathrm{TVS}(\mathrm{t}-2))$ and demeaned by sample mean. Squared TVS growth is calculated using demeand TVS growth. Firm level Tobin's $Q$ is taken as log average $Q$ at time $t-1$. Columns (1)-(2) and (4)-(5) include firm FE. Columns (3) and (6) include firm $\times$ year FE, which absorbs CRUX ( $t$ ) and Log Tobin's $Q$ ( $t-1)$. All columns include industry $\times$ year FE, where industry is at 3-digit NAICS code level. Time ranges from 1998 to 2014. Number of observations is 133000 and number of firms is 2000 , both rounded to the nearest thousands.

*** $p<0.01, * * p<0.05,{ }^{*} p<0.1$ 
Table 7: Effect of Uncertainty on Manufacturing Establishment Level Investment Spikes

\begin{tabular}{|c|c|c|c|}
\hline \multirow[b]{2}{*}{ VARIABLES } & \multicolumn{3}{|c|}{ Dependent Variable: Indicator Arithmetic Investment Rate $\geq 20 \%$ (t) } \\
\hline & $(1)$ & $(2)$ & (3) \\
\hline $\operatorname{CRUX}(\mathrm{t})$ & $\begin{array}{c}-0.116^{* *} \\
{[0.0527]}\end{array}$ & $\begin{array}{l}-0.114 * * \\
{[0.0526]}\end{array}$ & \\
\hline TVS Growth $(\Delta \ln \mathrm{t}-1)$ & $\begin{array}{c}0.0405 * * * \\
{[0.00489]}\end{array}$ & $\begin{array}{c}0.0373 * * * \\
{[0.00468]}\end{array}$ & $\begin{array}{c}0.0371 * * * \\
{[0.00462]}\end{array}$ \\
\hline $\operatorname{CRUX}(\mathrm{t}) \times$ TVS Growth $(\Delta \ln \mathrm{t}-1)$ & $\begin{array}{c}-0.298 * * * \\
{[0.0875]}\end{array}$ & $\begin{array}{c}-0.273 * * * \\
{[0.0861]}\end{array}$ & $\begin{array}{c}-0.290 * * * \\
{[0.0882]}\end{array}$ \\
\hline TVS Growth ( $\Delta \ln \mathrm{t}-1)$ squared & & $\begin{array}{c}0.00691 * * * \\
{[0.00145]}\end{array}$ & $\begin{array}{c}0.00609 * * * \\
{[0.00136]}\end{array}$ \\
\hline Log Tobin's Q (t-1) & & $\begin{array}{c}0.0157^{* * *} \\
{[0.00510]}\end{array}$ & \\
\hline Firm Fixed Effects & $\sqrt{ }$ & $\sqrt{ }$ & \\
\hline Firm $\times$ Year Fixed Effects & & & v \\
\hline Industry $\times$ Year Fixed Effects & $\sqrt{ }$ & $\sqrt{ }$ & $\sqrt{ }$ \\
\hline R-squared & 0.071 & 0.072 & 0.214 \\
\hline
\end{tabular}

Notes: Standard errors are clustered at firm level. Dependent variable is an indicator $=1$ if $(\mathrm{K}(\mathrm{t})-\mathrm{K}(\mathrm{t}-$ 1)) $/ \mathrm{K}(\mathrm{t}-1) \geq 20 \%$ and $=0$ if otherwise, where $\mathrm{K}$ is establishment's total capital stock. Firm level uncertainty measure CRUX is at time $t$, which as mentioned in the text captures firm uncertainty at time $t-1$. Establishment level TVS (total value of shipment) growth is calculated as $\log (T V S(t-1))-\log (T V S(t-2))$ and demeaned by sample mean. Squared TVS growth is calculated using demeand TVS growth. Firm level Tobin's $Q$ is taken as log average $Q$ at time t-1. Columns (1) and (2) include firm FE. Column ( 3 ) includes firm $\times$ year FE, which absorbs CRUX ( $t$ ) and Log Tobin's $Q(t-1)$. All columns include industry $\times$ year FE, where industry is at 3-digit NAICS code level. Time ranges from 1998 to 2014. Number of observations is 133000 and number of firms is 2000 , both rounded to the nearest thousands.

$* * * p<0.01, * * p<0.05, * p<0.1$ 
Table 8: Effect of Uncertainty on Firm Establishment Growth Rate ( $\Delta \mathrm{DHS})$

\begin{tabular}{|c|c|c|c|c|c|c|}
\hline \multirow[b]{2}{*}{ VARIABLES } & \multicolumn{6}{|c|}{ Dependent Variable: DHS Change in Number of Establishments ( $\Delta \mathrm{dhs}, \mathrm{t})$} \\
\hline & (1) & $(2)$ & (3) & (4) & (5) & (6) \\
\hline $\operatorname{CRUX}(\mathrm{t})$ & $\begin{array}{c}-0.145^{*} \\
{[0.0874]}\end{array}$ & $\begin{array}{c}-0.12 \\
{[0.0866]}\end{array}$ & $\begin{array}{c}-0.13 \\
{[0.0864]}\end{array}$ & $\begin{array}{c}-0.129 \\
{[0.0864]}\end{array}$ & $\begin{array}{c}-0.13 \\
{[0.0863]}\end{array}$ & $\begin{array}{c}-0.129 \\
{[0.0863]}\end{array}$ \\
\hline Sales Growth $(\Delta \ln \mathrm{t}-1)$ & & $\begin{array}{c}0.0663 * * * \\
{[0.00867]}\end{array}$ & $\begin{array}{c}0.0884 * * * \\
{[0.0123]}\end{array}$ & $\begin{array}{c}0.0854 * * * \\
{[0.0123]}\end{array}$ & $\begin{array}{c}0.0884 * * * \\
{[0.0124]}\end{array}$ & $\begin{array}{c}0.0853 * * * \\
{[0.0124]}\end{array}$ \\
\hline CRUX $(t) \times$ Sales Growth $(\Delta \ln t-1)$ & & & $\begin{array}{c}-0.529 * * * \\
{[0.199]}\end{array}$ & $\begin{array}{c}-0.521^{* * *} \\
{[0.198]}\end{array}$ & $\begin{array}{c}-0.530^{* * *} \\
{[0.199]}\end{array}$ & $\begin{array}{c}-0.527^{* * *} \\
{[0.198]}\end{array}$ \\
\hline Sales Growth $(\Delta \ln \mathrm{t}-1)$ squared & & & & & $\begin{array}{c}-0.0000843 \\
{[0.00291]}\end{array}$ & $\begin{array}{c}-0.000584 \\
{[0.00287]}\end{array}$ \\
\hline Log Tobin's Q (t-1) & & & & $\begin{array}{c}0.0334^{* * *} \\
{[0.00709]} \\
\end{array}$ & & $\begin{array}{l}0.0335 * * * \\
{[0.00711]} \\
\end{array}$ \\
\hline Firm Fixed Effects & $\mathrm{v}$ & $\mathrm{v}$ & 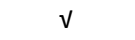 & $v$ & $\mathrm{v}$ & $\mathrm{v}$ \\
\hline Industry $\times$ Year Fixed Effects & $\mathrm{v}$ & $\mathrm{v}$ & $\mathrm{v}$ & $\mathrm{v}$ & $\mathrm{v}$ & $\mathrm{v}$ \\
\hline R-squared & 0.23 & 0.233 & 0.233 & 0.234 & 0.233 & 0.234 \\
\hline
\end{tabular}

Notes: Standard errors are clustered at firm level. Dependent variable is calculated as (est $(\mathrm{t})$-est $(\mathrm{t}-1)) /(0.5 \times(\operatorname{est}(\mathrm{t})+\mathrm{est}(\mathrm{t}-1)))$ where est is firm's total number of establishments. Firm uncertainty measure CRUX is at time $t$, which as mentioned in the text captures firm uncertainty at time $\mathrm{t}-1$. Sales growth is calculated as $\log (\operatorname{Sales}(\mathrm{t}-1))-\log (\operatorname{Sales}(\mathrm{t}-2))$ and demeaned by sample mean. Squared sales growth is calculated using demeand sales growth. Tobin's $Q$ is taken as log average $Q$ at time $t-1$. All of the regression specifications include firm FE. All columns include firm and industry $\times$ year FE, where industry is at 3-digit NAICS code level. Time ranges from 1994 to 2014. Number of observations is 55000 and number of firms is 6000 , both rounded to the nearest thousands.

$* * * p<0.01, * * p<0.05, * p<0.1$

Table 9: Effect of Uncertainty on Firm Establishment Growth Rate Decomposition $(\Delta \mathrm{DHS})$

\begin{tabular}{|c|c|c|c|c|c|}
\hline \multirow[b]{3}{*}{ VARIABLES } & \multicolumn{5}{|c|}{ Dependent Variable: DHS Change in Establishment ( $\Delta \mathrm{dhs}, \mathrm{t})$} \\
\hline & $(1)$ & (2) & (3) & (4) & (5) \\
\hline & Total & Birth & Death & Acquisition & Divestiture \\
\hline \multirow[t]{2}{*}{$\operatorname{CRUX}(\mathrm{t})$} & -0.13 & $-0.144 * * *$ & -0.00786 & $-0.0649 * *$ & $0.0865^{*}$ \\
\hline & {$[0.0864]$} & {$[0.0410]$} & {$[0.0521]$} & {$[0.0297]$} & {$[0.0450]$} \\
\hline \multirow[t]{2}{*}{ Sales Growth $(\Delta \ln \mathrm{t}-1)$} & $0.0884 * * *$ & $0.0260 * * *$ & $0.0375 * * *$ & $0.0209 * * *$ & 0.00393 \\
\hline & [0.0123] & {$[0.00405]$} & {$[0.00691]$} & {$[0.00323]$} & [0.00733] \\
\hline \multirow[t]{2}{*}{ CRUX $(\mathrm{t}) \times$ Sales Growth $(\Delta \ln \mathrm{t}-1)$} & $-0.529 * * *$ & $-0.193 * * *$ & -0.169 & $-0.162 * * *$ & -0.00597 \\
\hline & [0.199] & {$[0.0576]$} & {$[0.140]$} & {$[0.0461]$} & {$[0.119]$} \\
\hline R-squared & 0.233 & 0.231 & 0.251 & 0.217 & 0.244 \\
\hline
\end{tabular}

Notes: Standard errors are clustered at firm level. Dependent variable is calculated as (est $(\mathrm{t})$-est $(\mathrm{t}-1)) /(0.5 \times(\operatorname{est}(\mathrm{t})+\mathrm{est}(\mathrm{t}-1)))$ in different margins. Column (1) represents firm's total number of establishments change. Columns (2)-(5) represent firm's establishment change from birth, death, acquisition and divestiture. Coefficients in Columns (2)-(5) should add up to coefficients in Column (1). Firm uncertainty measure CRUX is at time $t$, which as mentioned in the text captures firm uncertainty at time t-1. Sales growth is calculated as $\log (\operatorname{Sales}(\mathrm{t}-1))-\log (\operatorname{Sales}(\mathrm{t}-2))$ and demeaned by sample mean. All of the regression specifications include firm FE and industry $\times$ year FE, where industry is at 3-digit NAICS code level. Time ranges from 1994 to 2014 . Number of observations is 55000 and number of firms is 6000 , both rounded to the nearest thousands.

$* * * p<0.01, * * p<0.05, * p<0.1$ 
Table 10: Effect of Uncertainty on Firm Employment Growth Rate $(\Delta \mathrm{DHS})$

\begin{tabular}{|c|c|c|c|c|c|c|}
\hline \multirow[b]{2}{*}{ VARIABLES } & \multicolumn{6}{|c|}{ Dependent Variable: DHS Change in Employment ( $\Delta \mathrm{dhs}, \mathrm{t})$} \\
\hline & (1) & $(2)$ & (3) & (4) & (5) & (6) \\
\hline $\operatorname{CRUX}(\mathrm{t})$ & $\begin{array}{c}-0.241 * * * \\
{[0.0872]}\end{array}$ & $\begin{array}{c}-0.191 * * \\
{[0.0860]}\end{array}$ & $\begin{array}{l}-0.202 * * \\
{[0.0849]}\end{array}$ & $\begin{array}{l}-0.199 * * \\
{[0.0843]}\end{array}$ & $\begin{array}{l}-0.204 * * \\
{[0.0848]}\end{array}$ & $\begin{array}{c}-0.201 * * \\
{[0.0842]}\end{array}$ \\
\hline Sales Growth $(\Delta \ln \mathrm{t}-1)$ & & $\begin{array}{c}0.132^{* * *} \\
{[0.0113]}\end{array}$ & $\begin{array}{c}0.155^{* * *} \\
{[0.0158]}\end{array}$ & $\begin{array}{l}0.148 * * * \\
{[0.0155]}\end{array}$ & $\begin{array}{l}0.155^{* * *} \\
{[0.0158]}\end{array}$ & $\begin{array}{c}0.147 * * * \\
{[0.0155]}\end{array}$ \\
\hline CRUX $(t) \times$ Sales Growth $(\Delta \ln t-1)$ & & & $\begin{array}{c}-0.560 * * \\
{[0.235]}\end{array}$ & $\begin{array}{c}-0.541 * * \\
{[0.232]}\end{array}$ & $\begin{array}{c}-0.591 * * \\
{[0.231]}\end{array}$ & $\begin{array}{c}-0.584^{* * *} \\
{[0.226]}\end{array}$ \\
\hline Sales Growth ( $\Delta \ln \mathrm{t}-1)$ squared & & & & & $\begin{array}{c}-0.003 \\
{[0.00395]}\end{array}$ & $\begin{array}{l}-0.00421 \\
{[0.00383]}\end{array}$ \\
\hline Log Tobin's Q (t-1) & & & & $\begin{array}{l}0.0806 * * * \\
{[0.00778]} \\
\end{array}$ & & $\begin{array}{l}0.0814^{* * *} \\
{[0.00780]}\end{array}$ \\
\hline Firm Fixed Effects & $\mathrm{v}$ & $\mathrm{v}$ & $v$ & $\mathrm{v}$ & $v$ & $v$ \\
\hline Industry $\times$ Year Fixed Effects & 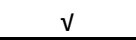 & $v$ & $v$ & $\sqrt{ }$ & $v$ & $v$ \\
\hline R-squared & 0.241 & 0.253 & 0.253 & 0.256 & 0.253 & 0.257 \\
\hline
\end{tabular}

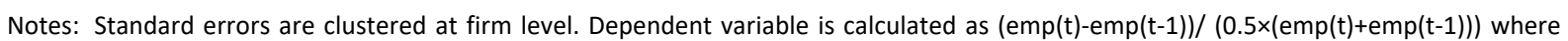
emp is firm's total employment. Firm uncertainty measure CRUX is at time $t$, which as mentioned in the text captures firm uncertainty at time $\mathrm{t}-1$. Sales growth is calculated as $\log (\operatorname{Sales}(\mathrm{t}-1))-\log (\operatorname{Sales}(\mathrm{t}-2))$ and demeaned by sample mean. Squared sales growth is calculated using demeand sales growth. Tobin's $Q$ is taken as log average $Q$ at time $t-1$. All of the regression specifications include firm FE. All columns include firm and industry $\times$ year FE, where industry is at 3-digit NAICS code level. Time ranges from 1994 to 2014. Number of observations is 55000 and number of firms is 6000 , both rounded to the nearest thousands.

$* * * p<0.01, * * p<0.05, * p<0.1$ 
Table 11: Effect of Uncertainty on Firm Employment Growth Rate Decomposition $(\Delta \mathrm{DHS})$

\begin{tabular}{|c|c|c|c|c|c|c|c|c|}
\hline \multirow{4}{*}{ VARIABLES } & \multicolumn{8}{|c|}{ Dependent Variable: DHS Change in Employment ( $\Delta$ dhs, $\mathrm{t})$} \\
\hline & \multirow[t]{2}{*}{$(1)$} & $(2)$ & (3) & (4) & (5) & (6) & (7) & (8) \\
\hline & & \multicolumn{4}{|c|}{ Extensive Margin } & \multicolumn{3}{|c|}{ Continuer } \\
\hline & Total & Birth & Death & Acquisition & Divestiture & Net & Creation & Destruction \\
\hline \multirow[t]{2}{*}{$\operatorname{CRUX}(\mathrm{t})$} & $-0.202 * *$ & $-0.105 * * *$ & -0.0361 & $-0.0463^{*}$ & $0.0841 *$ & $-0.0987 * *$ & $-0.0566 *$ & -0.0421 \\
\hline & [0.0849] & [0.0305] & [0.0448] & {$[0.0276]$} & [0.0462] & [0.0484] & [0.0294] & {$[0.0356]$} \\
\hline \multirow[t]{2}{*}{ Sales Growth ( $\Delta \ln \mathrm{t}-1)$} & $0.155^{* * *}$ & $0.0219 * * *$ & $0.0331 * * *$ & $0.0247 * * *$ & 0.00464 & $0.0707 * * *$ & $0.0377^{* * *}$ & $0.0330 * * *$ \\
\hline & [0.0158] & {$[0.00349]$} & {$[0.00692]$} & {$[0.00375]$} & {$[0.00830]$} & {$[0.00982]$} & {$[0.00473]$} & {$[0.00733]$} \\
\hline \multirow[t]{2}{*}{ CRUX $(t) \times$ Sales Growth $(\Delta \ln t-1)$} & $-0.560 * *$ & $-0.185^{* * *}$ & -0.114 & $-0.202 * * *$ & 0.0495 & -0.109 & $-0.164 * * *$ & 0.0552 \\
\hline & {$[0.235]$} & {$[0.0483]$} & [0.137] & {$[0.0484]$} & {$[0.142]$} & {$[0.166]$} & {$[0.0633]$} & [0.134] \\
\hline R-squared & 0.253 & 0.236 & 0.259 & 0.231 & 0.249 & 0.192 & 0.236 & 0.236 \\
\hline
\end{tabular}

Notes: Standard errors are clustered at firm level. Dependent variable is calculated as (emp(t)-emp(t-1))/ $(0.5 \times(e m p(t)+e m p(t-1)))$ in different margins. Column (1) represents firm's total employment change. Columns (2)-(5) represent firm's employment change from establishment birth, death, acquisition and divestiture. Column (6) represents gross employment change from firm's continuing establishments. Columns (7)-(8) represent job creation and destruction in firm's continuing establishments. Coefficients in Columns (2)-(6) should add up to coefficients in Column (1). Coefficients in Columns (7)-(8) should add up to coefficients in Column (6). Firm uncertainty measure CRUX is at time $t$, which as mentioned in the text captures firm uncertainty at time t-1. Sales growth is calculated as log(Sales(t-1)) - log(Sales(t-2)) and demeaned by sample mean. All of the regression specifications include firm FE and industry $\times$ year FE, where industry is at 3-digit NAICS code level. Time ranges from 1994 to 2014. Number of observations is 55000 and number of firms is 6000 , both rounded to the nearest thousands.

*** $\mathrm{p}<0.01, * * \mathrm{p}<0.05, * \mathrm{p}<0.1$ 
Table 12: Effect of Peer vs Own Uncertainty on Manufacturing Establishment Level Total Investment Rate $(\Delta \ln )$

\begin{tabular}{|c|c|c|c|c|c|c|}
\hline \multirow[b]{2}{*}{ VARIABLES } & \multicolumn{6}{|c|}{ Dependent Variable: Log Total Investment Rate $(\Delta \mathrm{ln}, \mathrm{t})$} \\
\hline & $(1)$ & $(2)$ & (3) & (4) & $(5)$ & $(6)$ \\
\hline Peer CRUX (t) & $\begin{array}{c}-0.237^{*} \\
{[0.141]}\end{array}$ & $\begin{array}{c}-0.268^{*} \\
{[0.137]}\end{array}$ & $\begin{array}{c}-0.219 \\
{[0.140]}\end{array}$ & $\begin{array}{c}-0.249 * \\
{[0.136]}\end{array}$ & & \\
\hline Peer CRUX $(\mathrm{t}) \times$ TVS Growth $(\Delta \ln \mathrm{t}-1)$ & $\begin{array}{c}-0.734^{* * *} \\
{[0.258]}\end{array}$ & $\begin{array}{l}-0.512^{*} \\
{[0.308]}\end{array}$ & $\begin{array}{c}-0.702 * * * \\
{[0.256]}\end{array}$ & $\begin{array}{l}-0.496 \\
{[0.305]}\end{array}$ & $\begin{array}{c}-0.814^{* * *} \\
{[0.277]}\end{array}$ & $\begin{array}{c}-0.594 * \\
{[0.312]}\end{array}$ \\
\hline $\operatorname{CRUX}(\mathrm{t})$ & & $\begin{array}{c}-0.0768^{* *} \\
{[0.0344]}\end{array}$ & & $\begin{array}{c}-0.0739 * * \\
{[0.0346]}\end{array}$ & & \\
\hline $\operatorname{CRUX}(\mathrm{t}) \times$ TVS Growth $(\Delta \ln \mathrm{t}-1)$ & & $\begin{array}{l}-0.248^{*} \\
{[0.136]}\end{array}$ & & $\begin{array}{c}-0.232 * \\
{[0.132]}\end{array}$ & & $\begin{array}{c}-0.248^{*} \\
{[0.133]}\end{array}$ \\
\hline TVS Growth $(\Delta \ln \mathrm{t}-1)$ & $\begin{array}{c}0.0333 * * * \\
{[0.00368]}\end{array}$ & $\begin{array}{c}0.0430 * * * \\
{[0.00766]}\end{array}$ & $\begin{array}{c}0.0315^{* * *} \\
{[0.00350]}\end{array}$ & $\begin{array}{l}0.0406 * * * \\
{[0.00724]}\end{array}$ & $\begin{array}{c}0.0315^{* * *} \\
{[0.00361]}\end{array}$ & $\begin{array}{c}0.0411^{* * *} \\
{[0.00688]}\end{array}$ \\
\hline TVS Growth ( $\Delta \ln \mathrm{t}-1)$ squared & & & $\begin{array}{c}0.00547^{* * *} \\
{[0.00189]}\end{array}$ & $\begin{array}{c}0.00538^{* * *} \\
{[0.00187]}\end{array}$ & $\begin{array}{c}0.00493 * * \\
{[0.00191]}\end{array}$ & $\begin{array}{c}0.00486 * * \\
{[0.00190]}\end{array}$ \\
\hline Log Tobin's Q (t-1) & & & $\begin{array}{c}0.0152^{* * *} \\
{[0.00317]} \\
\end{array}$ & $\begin{array}{c}0.0152^{* * *} \\
{[0.00316]} \\
\end{array}$ & & \\
\hline Firm Fixed Effects & $v$ & $v$ & $\mathrm{~V}$ & $v$ & & \\
\hline Firm $\times$ Year Fixed Effects & & & & & $\mathrm{v}$ & $\mathrm{v}$ \\
\hline Industry $\times$ Year Fixed Effects & $\sqrt{ }$ & $\sqrt{ }$ & $\sqrt{ }$ & $\sqrt{ }$ & $\mathrm{v}$ & $\mathrm{v}$ \\
\hline R-squared & 0.081 & 0.081 & 0.083 & 0.083 & 0.227 & 0.227 \\
\hline
\end{tabular}

Notes: Standard errors are clustered at firm level. Dependent variable is calculated as $\log (K(t))-\log (K(t-1))$ where $K$ is establishment's total capital stock. Firm level uncertainty measure CRUX is at time t, which as mentioned in the text captures firm uncertainty at time t-1. Uncertainty measure of establishment's peers is calculated by taking the average of firm FE demeaned CRUX measure of all establishments from other firms within the same industry (4-digit NAICS code). Establishment level TVS (total value of shipment) growth is calculated as $\log (T V S(t-1))-\log (T V S(t-2))$ and demeaned by sample mean. Squared TVS growth is calculated using demeand TVS growth. Firm level Tobin's $Q$ is taken as log average $Q$ at time $t-1$. Columns (1)-(4) include firm FE. Columns (5)-(6) include firm $\times$ year FE, which absorbs CRUX (t), Peer CRUX $(t)$ and Log Tobin's Q (t-1). All columns include industry $\times$ year FE, where industry is at 3-digit NAICS code level. Time ranges from 1998 to 2014. Number of observations is 133000 and number of firms is 2000 , both rounded to the nearest thousands.

$* * * p<0.01, * * p<0.05, * p<0.1$ 
Table 13: Effect of Industry Uncertainty on Manufacturing Establishment Level Total Investment Rate $(\Delta \ln )$ - Full ASM/CM Manufacturing Sample

\begin{tabular}{|c|c|c|c|}
\hline \multirow[b]{2}{*}{ VARIABLES } & \multicolumn{3}{|c|}{ Dependent Variable: Log Total Investment Rate $(\Delta \ln , \mathrm{t})$} \\
\hline & $(1)$ & (2) & $(3)$ \\
\hline Industry CRUX (t) & $\begin{array}{c}-0.184^{* * *} \\
{[0.0565]}\end{array}$ & $\begin{array}{c}-0.186 * * * \\
{[0.0564]}\end{array}$ & \\
\hline TVS Growth $(\Delta \ln \mathrm{t}-1)$ & $\begin{array}{c}0.0230 * * * \\
{[0.00172]}\end{array}$ & $\begin{array}{c}0.0223 * * * \\
{[0.00168]}\end{array}$ & $\begin{array}{c}0.0245 * * * \\
{[0.00239]}\end{array}$ \\
\hline Industry CRUX $(\mathrm{t}) \times$ TVS Growth $(\Delta \ln \mathrm{t}-1)$ & $\begin{array}{c}-0.370 * * * \\
{[0.102]}\end{array}$ & $\begin{array}{c}-0.324 * * * \\
{[0.0994]}\end{array}$ & $\begin{array}{c}-0.389 * * * \\
{[0.150]}\end{array}$ \\
\hline TVS Growth $(\Delta \ln t-1)$ squared & & $\begin{array}{l}0.00392 * * * \\
{[0.000875]} \\
\end{array}$ & $\begin{array}{c}0.00432 * * * \\
{[0.00116]} \\
\end{array}$ \\
\hline Firm Fixed Effects & v & $v$ & \\
\hline Firm $\times$ Year Fixed Effects & & & $\mathrm{v}$ \\
\hline Industry $\times$ Year Fixed Effects & $\sqrt{ }$ & $\sqrt{ }$ & $\sqrt{ }$ \\
\hline R-squared & 0.124 & 0.125 & 0.423 \\
\hline \multicolumn{4}{|c|}{$\begin{array}{l}\text { Notes: Standard errors are clustered at industry (4-digit NAICS) } \times \text { year level. Dependent variable is } \\
\text { calculated as } \log (\mathrm{K}(\mathrm{t}))-\log (\mathrm{K}(\mathrm{t}-1)) \text { where } \mathrm{K} \text { is establishment's total capital stock. Industry level uncertainty } \\
\text { measure Inudustry CRUX }(\mathrm{t}) \text { is calculated by taking equally weighted average of firm FE demeaned CRUX } \\
\text { measure of all establishments within the same industry (4-digit NAICS code). Establishment level TVS (total } \\
\text { value of shipment) growth is calculated as } \log (\mathrm{TVS}(\mathrm{t}-1))-\log (\mathrm{TVS}(\mathrm{t}-2)) \text { and demeaned by sample mean. } \\
\text { Squared TVS growth is calculated using demeand TVS growth. Columns }(1)-(2) \text { include firm FE, Column (3) } \\
\text { includes firm } \times \text { year FE, which absorbs Inudstry CRUX (t). All columns include industry } \times \text { year FE, where } \\
\text { industry is at } 3 \text {-digit NAICS code level. Time ranges from } 1998 \text { to } 2014 \text {. Number of observations is } 472000 \\
\text { and number of firms is } 21000 \text {, both rounded to the nearest thousands. } \\
* * * p<0.01, * * p<0.05, * p<0.1\end{array}$} \\
\hline
\end{tabular}


Table 14: Effects of Uncertainty on Corporate Investment Rate Under Heterogeneous Response to Aggregate Shocks ( $\Delta \ln$, Compustat)

\begin{tabular}{|c|c|c|c|}
\hline \multirow[b]{2}{*}{ VARIABLES } & \multicolumn{3}{|c|}{ Dependent Variable: Log Change in Capital Stock $K(\Delta \ln , t)$} \\
\hline & (1) & $(2)$ & (3) \\
\hline \multirow[t]{2}{*}{$\operatorname{CRUX}(\mathrm{t})$} & $-0.300 * * *$ & $-0.374 * * *$ & $-0.375 * * *$ \\
\hline & {$[0.0425]$} & {$[0.0503]$} & {$[0.0516]$} \\
\hline \multirow[t]{2}{*}{ Sales Growth $(\Delta \ln \mathrm{t}-1)$} & $0.0775^{* * *}$ & $0.0745^{* * *}$ & $0.0774 * * *$ \\
\hline & {$[0.00546]$} & {$[0.00753]$} & {$[0.00747]$} \\
\hline \multirow[t]{2}{*}{$\operatorname{CRUX}(\mathrm{t}) \times$ Sales Growth $(\Delta \ln \mathrm{t}-1)$} & $-0.494 * * *$ & $-0.440 * * *$ & $-0.436 * * *$ \\
\hline & {$[0.0705]$} & {$[0.102]$} & {$[0.0985]$} \\
\hline Firm Fixed Effects & $\sqrt{ }$ & $\sqrt{ }$ & $\sqrt{ }$ \\
\hline Industry $\times$ Year Fixed Effects & $\sqrt{ }$ & $\sqrt{ }$ & $\sqrt{ }$ \\
\hline Heterogeneous Response to Aggregate CRUX & & $\sqrt{ }$ & \\
\hline Heterogeneous Response to Industry CRUX & & & $\sqrt{ }$ \\
\hline Observations & 93,741 & 93,741 & 93,741 \\
\hline R-squared & 0.405 & 0.695 & 0.685 \\
\hline Number of Firms & 10,445 & 10,445 & 10,445 \\
\hline CRUX Coeff Equal to Baseline ( $p$-value) & & 0.257 & 0.256 \\
\hline CRUX $\times$ Sales Growth Coeff Equal to Baseline ( $p$-value) & & 0.654 & 0.625 \\
\hline
\end{tabular}

Notes: Standard errors are clustered at firm level. This table presents results of heterogeneity of response to common uncertainty shocks. Column (1) is the baseline investment regression results in the third column in Table 3. Column (2) includes heterogeneous response to aggregate uncertainty shocks (simple average of CRUX by year). Column (3) includes heterogeneous response to industry level uncertainty shocks (simple average of CRUX by industry $\times$ year). P-value of Wald test of CRUX $(t)$ and CRUX $(t) \times$ Sales Growth $(\Delta \ln t-1)$ between column (1) vs (2) and column (1) vs (3) are reported. All columns include firm fixed effects and industry $\times$ year fixed effects. Time ranges from 1994 to 2006.

$* * * p<0.01, * * p<0.05, * p<0.1$ 


\section{A Data Appendix}

\section{A.1 SEC EDGAR Data Parsing}

We download all the raw text of annual and quarterly reports24 from 1994 to 2016 through links provided by EDGAR that were active as of January 2018. There are 1,000,313 documents and they are cleaned using Python 3.5.4 in the following steps:

1. Rewrite the entire text into lower case.

2. Remove all built-in graphic, zip, excel, pdf, xml documents indicated by their tags (e.g. all characters between "<type $>$ graphic" and " $<$ /document $>$ " are removed).

3. Extract "conformed period of report" for each document 25

4. Remove titles of each sub section of the document.

5. Remove the header and footer of the documents (e.g. all characters in front of "</sec-header $>$ ").

6. Remove phrase "table of contents". The phrase might show up at the end of each page to link the reader back to the table of contents.

7. Remove all XBRL (eXtensible Business Reporting Language) which is provided by the companies for machine reading.

8. Remove HTML entities, carriages and non ASCII encoded characters.

9. Remove HTML tags.

10. Remove punctuation.

11. Create variable to indicate whether or not the document contains "Item 1A. Risk Factors" section by scanning the text and locate the position of the phrase "item 1a risk factors".

12. Remove tables that contain a significant amount of digits. Tables are usually non textual information, such as balance sheets. However, some documents use tables to report everything including descriptive contents. It would like regular text on the EDGAR website, but is marked up as a table in the underlying text file. Therefore, we keep the tables whose ratio of digits out of all characters is below that of the entire document 26

13. Remove digits.

14. Count the frequency of "uncertain", and a dictionary of "uncertain" related words obtained from combining synonyms of "uncertain", "uncertainty", "risk", "risky" and their derivatives 27 15. Count number of words, number of distinct words, number of words when "stop words" are removed 28 ,

\footnotetext{
${ }^{24}$ Those include 10-K, 10-K405, 10-KSB, 10-Q, 10-QSB and their amendments. Some 10-K reports such as transition reports $10-\mathrm{KT}$ are excluded from the sample.

${ }^{25}$ Conformed period of report is usually coded in a standard way in the report. We hand checked the documents whose "conformed period of report" is irregularly coded in the text.

${ }^{26}$ We also keep a version that removes all the tables since only a small fraction of companies use table to report textual descriptive contents in some of their reports. Our results are robust to this version of measure.

${ }^{27}$ We use 2007 version of Oxford dictionary and thesaurus as our reference and word list from Hassan et al. (2017)

${ }^{28}$ List of stemmed stop words are from python package NLTK PorterStemmer. The list: 'a', 'about', 'above', 'after', 'again', 'against', 'ain', 'all', 'am', 'an', 'and', 'any', 'are', 'aren', 'as', 'at', 'be', 'because', 'been', 'before', 'being', 'below', 'between', 'both', 'but', 'by', 'can', 'couldn', 'd', 'did', 'didn', 'do', 'does', 'doesn', 'doing', 'don',
} 
16. Stem the whole document and recount and repeat step 15.

With the information collected from the cleaned text we can calculate useful characteristics of each filing document, such as average frequency of each word, ratio of number of distinct words in stemmed and unstemmed documents, etc. We also pick up some policy changes that have potential impacts on our measure. We count "uncertain tax positions" frequency as it is a proper noun on tax issues that firms start reporting in mid 2000s complying accounting rule FIN 48, which requires publicly traded entities to disclose income tax risks. Another policy change is the requirement of risk factors disclosure. SEC mandate firms to report RISK FACTORS section (usually in item 1A) in their annual reports from fiscal year ending in 2005. Most quarterly reports comply with the requirement as well. The summary statistics on Edgar parsing results are reported in Table A2.

\section{A.2 COMPUSTAT, CRSP and Option Metrics}

This section provides detailed information on how COMPUSTAT firm level data, realized volatility measure and implied volatility is created.

We download COMPUSTAT-Capital IQ North America Fundamentals Annual data from WRDS. In order to match with SEC EDGAR data (CRUX), all missing CIKs are removed. We replace missing fiscal year by COMPUSTAT defined variable datayear if data date is in the second half of the year or by datayear - 1 if data date is in the first half of the year. We take the maximum value of the variables of interest if there are duplicate observations for firms within the same year. Negative sales (sale) and capital investment (capx) are dropped. Tobin's Q is calculated by $\left(c s h o \times p r c c \_f+a t-c e q\right) / a t$ as described in the main text. Missing capital investment (capx) is interpolated by the average of capital investment of the preceding and following years if neither of the two is missing. We start calculating capital stock at the year total property, plant and equipment (ppent) is first observed and set the first ppent $=K_{i 0}$. Then capital stock for each year is calculated by perpetual inventory formula $K_{i t}=P P I_{t}\left((1-r) K_{i t-1}+c a p x_{i t-1}\right)$. Capital investment is taken at $t-1$ as investment takes time. Construction of sales growth, taking logs, DHS and lags

are straightforward. The empirical analysis is on the matched COMPUSTAT-EDGAR data where missing data are dropped.

We download firm level stock return data from CRSP to construct realized volatility. The CRSP U.S. Stock database contains end-of-day and end-of-month prices on primary listings from major stock exchange markets, including NYSE, NASDAQ, etc. We calculate the annual volatility of monthly holding period return $(R E T)$ as realized volatility of the firm within the year. Then we take the lag and match realized volatility data from CRSP with COMPUSTAT firm level data to

'down', 'during', 'each', 'few', 'for', 'from', 'further', 'had', 'hadn', 'has', 'hasn', 'have', 'haven', 'having', 'he', 'her', 'here', 'hers', 'herself', 'him', 'himself', 'his', 'how', 'i', 'if', 'in', 'into', 'is', 'isn', 'it', 'its', 'itself', 'just', 'll', 'm', 'ma', 'me', 'mightn', 'more', 'most', 'mustn', 'my', 'myself', 'needn', 'no', 'nor', 'not', 'now', 'o', 'of', 'off', 'on', 'once', 'only', 'or', 'other', 'our', 'ours', 'ourselves', 'out', 'over', 'own', 're', 's', 'same', 'shan', 'she', 'should', 'shouldn', 'so', 'some', 'such', 't', 'than', 'that', 'the', 'their', 'theirs', 'them', 'themselves', 'then', 'there', 'these', 'they', 'this', 'those', 'through', 'to', 'too', 'under', 'until', 'up', 've', 'very', 'was', 'wasn', 'we', 'were', 'weren', 'what', 'when', 'where', 'which', 'while', 'who', 'whom', 'why', 'will', 'with', 'won', 'wouldn', 'y', 'you', 'your', 'yours', 'yourself', 'yourselves'. 
evaluate the effect of realized volatility on corporate behavior. Our result is robust if we use daily holding period return to calculate realized volatility.

Implied volatility is downloaded from Option Metrics Standardized Options. The construction of annual implied volatility follows Barrero, Bloom and Wright (2017). First, we take the average of firm-day implied volatility across calls and puts. Then we compute the annual measure of implied volatility by taking the Euclidean mean of daily implied volatility within the year: impl vol ${ }_{i \text {,year }}=$ $\sqrt{\frac{1}{\# \text { of days }} \sum_{\# \text { of days }} \mathrm{impl} \mathrm{vol}_{i, \text { day }}}$. Similarly, we take the lag and match implied volatility data from Option Metrics with COMPUSTAT firm level data to evaluate the effect of implied volatility on corporate investment.

\section{A.2.1 Propensity Score Weighting}

The propensity scores are constructed by fitting logit specifications for each fiscal year

$$
\log \frac{p\left(\boldsymbol{X}_{i t}\right)}{1-p\left(\boldsymbol{X}_{i t}\right)}=\boldsymbol{\theta}_{t} \boldsymbol{X}_{i t}
$$

which implies that $\mathbb{P}\left(I_{i t}=1 \mid X_{i t}\right)=\frac{1}{1+e^{-\theta_{t} X_{i t}}}$ where $I_{i t}$ is the indicator equal to 1 if the firm/establishment is selected in the SEC EDGAR - COMPUSTAT- CENSUS matched sample. In the LBD, sample, the control variables $\boldsymbol{X}_{i t}$ include firm characteristics: 4-digit NAICS industry code, employment classes (1-249, 250-499, 500-999, 1000 or more), age class (1-5, 6-10, 11-15, 16-20, 21 years or more), payroll class (1 thousand dollars or less, 1-20, 20-200, 200-1000, 1000 thousands dollars or more), and indicator variable equal to 1 if the firm is included in the COMPUSTAT-BR bridge 29 To account for the fact that ASM is survey data and non-random, we modify our control variables in ASM/CM sample based on above specification. We use 10 establishment employment classes (1-9, 10-19, 20-29, 30-49, 50-99, 100-149, 150-249, 250-499, 500-999, 1000 or more). The indicator variable equal to 1 if the establishment is both in the ASM/CM sample and the establishment operates in two consecutive years so we can compute investment rates. The inverse propensity scores allow us to estimate a weighted linear regression of the baseline model or to compute CRUX measure for industry level aggregates.

\footnotetext{
${ }^{29}$ We choose these classes based on Foster et al. (2016) and the propensity score model in Davis et al. (2014).
} 


\section{Appendix Tables}

Table A1: Summary Statistics - LBD

\begin{tabular}{|c|c|c|c|}
\hline VARIABLES & Mean & Std Dev & Share \\
\hline Total Employment Growth(A + B) & -0.630 & [39.1] & - \\
\hline A. Job Creation Rate $(a+b+c)$ & 16.830 & [23.3] & - \\
\hline a. Birth ( $\Delta$ dhs, Organic) & 4.450 & [13.5] & $26 \%$ \\
\hline b. Acquisition ( $\Delta$ dhs) & 3.280 & [13.2] & $19 \%$ \\
\hline c. Continuer ( $\Delta \mathrm{dhs}$, Organic) & 9.100 & [13.4] & $54 \%$ \\
\hline B. Job Destruction Rate $(d+e+f)$ & -17.460 & [30.4] & - \\
\hline d. Death ( $\Delta$ dhs, Organic) & -5.080 & [18.2] & $29 \%$ \\
\hline e. Divestiture ( $\Delta$ dhs) & -3.130 & [20.4] & $18 \%$ \\
\hline f. Continuer ( $\Delta$ dhs, Organic) & -9.250 & [14.6] & $53 \%$ \\
\hline Job Churning Rate $(a+b+c-d-e-f)$ & 34.290 & [37.6] & - \\
\hline Total Establishment Growth $(a+b+c+d)$ & -0.360 & [37.9] & - \\
\hline a. Birth $(\Delta \mathrm{dhs})$ & 7.550 & [17.8] & - \\
\hline b. Death ( $\Delta \mathrm{dhs})$ & -8.510 & [21.1] & - \\
\hline c. Acquisition ( $\Delta$ dhs) & 3.820 & [13.9] & - \\
\hline d. Divestiture ( $\Delta$ dhs) & -3.220 & {$[20]$} & - \\
\hline CRUX & 0.038 & {$[0.0317]$} & - \\
\hline Peer CRUX & -0.058 & [1.33] & - \\
\hline Peer CRUX (weighted) & -0.061 & {$[1.34]$} & - \\
\hline Lag Tobin's Q (log) & 0.399 & [0.529] & - \\
\hline Lag Sales Growth (log) & 0.0774 & {$[0.37]$} & - \\
\hline Lag Sales Growth $(\log )$ Squared & 0.143 & [1.258] & - \\
\hline Number of Observations & 55000 & & \\
\hline
\end{tabular}


Table A2: Summary Statistics - Parsed SEC Edgar Documents

\begin{tabular}{|c|c|c|c|c|c|c|}
\hline VARIABLES & $\mathrm{N}$ & mean & median & sd & $\min$ & $\max$ \\
\hline \multicolumn{7}{|c|}{ Original Document } \\
\hline Total Word Count & $1,000,313$ & 19,247 & 10,329 & 35,782 & 0 & $9,597,104$ \\
\hline Unique Word Count & $1,000,313$ & 1,690 & 1,392 & 1,850 & 0 & 350,324 \\
\hline Total Word Count (without stopwords) & $1,000,313$ & 11,357 & 6,116 & 23,385 & 0 & $7,334,912$ \\
\hline Unique Word Count (without stopwords) & $1,000,313$ & 1,602 & 1,301 & 1,841 & 0 & 350,197 \\
\hline Total Stopword Count & $1,000,313$ & 7,890 & 4,196 & 13,127 & 0 & $2,262,192$ \\
\hline Unique Stopword Count & $1,000,313$ & 88.11 & 91 & 18.11 & 0 & 137 \\
\hline "Uncertain" count & $1,000,313$ & 4.404 & 3 & 5.698 & 0 & 133 \\
\hline \multicolumn{7}{|c|}{ Stemmed Document } \\
\hline Unique Word Count & $1,000,313$ & 1,220 & 1,031 & 1,615 & 0 & 337,215 \\
\hline Unique Word Count (without stopwords) & $1,000,313$ & 1,137 & 944 & 1,610 & 0 & 337,139 \\
\hline Unique Stopword Count & $1,000,313$ & 83.22 & 86 & 15.75 & 0 & 122 \\
\hline
\end{tabular}


Table A3: Effect of Uncertainty on Firm Organic Employment Growth Rate $(\Delta \mathrm{DHS})$

\begin{tabular}{|c|c|c|c|c|}
\hline \multirow[b]{2}{*}{ VARIABLES } & \multicolumn{4}{|c|}{ Dependent Variable: DHS Change in Employment $(\Delta \mathrm{dhs}, \mathrm{t})$} \\
\hline & $\begin{array}{l}\text { (1) } \\
\text { Gross Job } \\
\text { Creation } \\
\end{array}$ & $\begin{array}{c}(2) \\
\text { Organic Job } \\
\text { Creation } \\
\end{array}$ & $\begin{array}{c}\text { (3) } \\
\text { Gross Job } \\
\text { Destruction }\end{array}$ & $\begin{array}{c}\text { (4) } \\
\text { Organic Job } \\
\text { Destruction }\end{array}$ \\
\hline $\operatorname{CRUX}(\mathrm{t})$ & $\begin{array}{c}-0.208 * * * \\
{[0.0493]}\end{array}$ & $\begin{array}{c}-0.162^{* * *} \\
{[0.0420]}\end{array}$ & $\begin{array}{l}0.00591 \\
{[0.0717]}\end{array}$ & $\begin{array}{c}-0.0782 \\
{[0.0570]}\end{array}$ \\
\hline Sales Growth $(\Delta \ln \mathrm{t}-1)$ & $\begin{array}{c}0.0842 * * * \\
{[0.00755]}\end{array}$ & $\begin{array}{c}0.0596 * * * \\
{[0.00610]}\end{array}$ & $\begin{array}{c}0.0707 * * * \\
{[0.0118]}\end{array}$ & $\begin{array}{c}0.0661 * * * \\
{[0.00768]}\end{array}$ \\
\hline CRUX $(\mathrm{t}) \times$ Sales Growth $(\Delta \ln \mathrm{t}-1)$ & $\begin{array}{c}-0.551 * * * \\
{[0.0969]} \\
\end{array}$ & $\begin{array}{c}-0.349 * * * \\
{[0.0786]} \\
\end{array}$ & $\begin{array}{c}-0.00899 \\
{[0.215]}\end{array}$ & $\begin{array}{l}-0.0585 \\
{[0.149]} \\
\end{array}$ \\
\hline R-squared & 0.283 & 0.276 & 0.291 & 0.3 \\
\hline
\end{tabular}

Notes: Standard errors are clustered at firm level. Dependent variable is calculated as (emp(t)-emp(t-1))/ $(0.5 \times(\mathrm{emp}(\mathrm{t})+\mathrm{emp}(\mathrm{t}-$ 1))) in different margins. Columns (1) represents firm's gross job creation, which is the sum of organic job creation and job creation from establishment acquisition. Columns (2) represents firm's organic job creation, which is the sum of job creation from establishment birth and continuing establishments. Columns (3) and (4) are similar but represent job destruction margin. Firm uncertainty measure CRUX is at time $t$, which as mentioned in the text captures firm uncertainty at time t- 1 . Sales growth is calculated as $\log (\operatorname{Sales}(\mathrm{t}-1))-\log (\operatorname{Sales}(\mathrm{t}-2))$ and demeaned by sample mean. All of the regression specifications include firm FE and industry $\times$ year FE, where industry is at 3-digit NAICS code level. Time ranges from 1994 to 2014. Number of observations is 55000 and number of firms is 6000 , both rounded to the nearest thousands.

$* * * \mathrm{p}<0.01, * * \mathrm{p}<0.05, * \mathrm{p}<0.1$

Table A4: Summary Statistics - ASM/CM Establishment Level Data (Full Sample)

\begin{tabular}{lcc}
\hline VARIABLES & Mean & Std Dev \\
\hline Industry CRUX (Equally-Weighted) & 0.00219 & {$[0.0126]$} \\
Industry CRUX (IPS-Weighted) & 0.00219 & {$[0.0126]$} \\
Log Total Investment Rate & 0.00654 & {$[0.152]$} \\
Investment Spike & 0.0475 & {$[0.213]$} \\
Log Structure Investment Rate & -0.000726 & {$[0.111]$} \\
Log Equipment Investment Rate & 0.0098 & {$[0.184]$} \\
Lag TVS growth (log) & 0.00697 & {$[0.417]$} \\
Lag TVS Growth (log) squared & 0.174 & {$[1.037]$} \\
\hline Number of Observations & 472000 & \\
\hline
\end{tabular}


Table A5: Effect of Industry Uncertainty on Equipment vs. Structure Investment Rate $(\Delta \ln )$

\begin{tabular}{|c|c|c|c|c|c|c|}
\hline \multirow[b]{2}{*}{ VARIABLES } & \multicolumn{3}{|c|}{ Log Equipment Investment Rate $(\Delta \ln , \mathrm{t})$} & \multicolumn{3}{|c|}{ Log Structure Investment Rate $(\Delta \ln , \mathrm{t})$} \\
\hline & (1) & $(2)$ & (3) & (4) & $(5)$ & $(6)$ \\
\hline \multirow[t]{2}{*}{ Industry CRUX (t) } & $-0.242 * * *$ & $-0.245^{* * *}$ & & -0.0342 & -0.0351 & \\
\hline & {$[0.0751]$} & {$[0.0750]$} & & [0.0345] & [0.0345] & \\
\hline \multirow[t]{2}{*}{ TVS Growth ( $\Delta \ln \mathrm{t}-1)$} & $0.0300 * * *$ & $0.0292 * * *$ & $0.0316^{* * *}$ & $0.00974 * * *$ & $0.00950 * * *$ & $0.0117^{* * *}$ \\
\hline & {$[0.00197]$} & {$[0.00192]$} & {$[0.00266]$} & [0.00121] & {$[0.00121]$} & {$[0.00174]$} \\
\hline \multirow[t]{2}{*}{ Industry CRUX $(\mathrm{t}) \times$ TVS Growth $(\Delta \ln \mathrm{t}-1)$} & $-0.508 * * *$ & $-0.458 * * *$ & $-0.547 * * *$ & $-0.158^{* *}$ & $-0.142^{* *}$ & $-0.205^{*}$ \\
\hline & [0.115] & [0.112] & {$[0.166]$} & {$[0.0727]$} & {$[0.0697]$} & [0.108] \\
\hline \multirow[t]{2}{*}{ TVS Growth $(\Delta \ln \mathrm{t}-1)$ squared } & & $0.00424 * * *$ & $0.00462 * * *$ & & $0.00132 * *$ & $0.00153^{*}$ \\
\hline & & {$[0.000937]$} & {$[0.00124]$} & & {$[0.000667]$} & {$[0.000854]$} \\
\hline Firm Fixed Effects & $v$ & v & & v & v & \\
\hline Firm $\times$ Year Fixed Effects & & & $\mathrm{V}$ & & & v \\
\hline Industry $\times$ Year Fixed Effects & $\mathrm{V}$ & 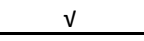 & $\mathrm{V}$ & 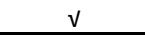 & $v$ & $\mathrm{~V}$ \\
\hline R-squared & 0.132 & 0.133 & 0.436 & 0.092 & 0.092 & 0.375 \\
\hline \multicolumn{7}{|c|}{ 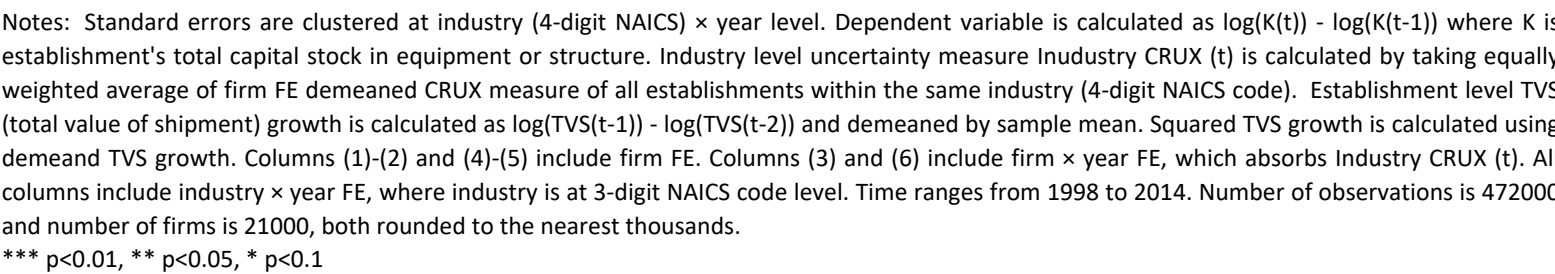 } \\
\hline
\end{tabular}

Table A6: Effects of High vs Low Uncertainty on Corporate Investment Rate $(\Delta \ln$, Compustat)

\begin{tabular}{|c|c|c|c|c|c|c|}
\hline \multirow[b]{2}{*}{ VARIABLES } & \multicolumn{6}{|c|}{ Dependent Variable: Log Change in Capital Stock K $(\Delta \ln , \mathrm{t})$} \\
\hline & (1) & $(2)$ & (3) & (4) & (5) & (6) \\
\hline High CRUX (t) & $\begin{array}{c}-0.0161 * * * \\
{[0.00241]}\end{array}$ & $\begin{array}{c}-0.0139 * * * \\
{[0.00240]}\end{array}$ & $\begin{array}{c}-0.0134^{* * *} \\
{[0.00235]}\end{array}$ & $\begin{array}{c}-0.0135^{* * *} \\
{[0.00235]}\end{array}$ & $\begin{array}{c}-0.0124 * * * \\
{[0.00232]}\end{array}$ & $\begin{array}{c}-0.0125^{* * *} \\
{[0.00232]}\end{array}$ \\
\hline Sales Growth $(\Delta \ln \mathrm{t}-1)$ & & & $\begin{array}{c}0.0749 * * * \\
{[0.00537]}\end{array}$ & $\begin{array}{c}0.0736 * * * \\
{[0.00526]}\end{array}$ & $\begin{array}{l}0.0689 * * * \\
{[0.00509]}\end{array}$ & $\begin{array}{r}0.0679 * * * \\
{[0.00500]}\end{array}$ \\
\hline High CRUX $(\mathrm{t}) \times$ Sales Growth $(\Delta \ln \mathrm{t}-1)$ & & & $\begin{array}{c}-0.0367 * * * \\
{[0.00591]}\end{array}$ & $\begin{array}{c}-0.0365 * * * \\
{[0.00591]}\end{array}$ & $\begin{array}{c}-0.0339 * * * \\
{[0.00570]}\end{array}$ & $\begin{array}{c}-0.0338^{* * *} \\
{[0.00570]}\end{array}$ \\
\hline Sales Growth ( $\Delta \mathrm{ln} \mathrm{t}-1)$ sqaured & & & & $\begin{array}{l}0.00319 * * * \\
{[0.000830]}\end{array}$ & & $\begin{array}{r}0.00248 * * * \\
{[0.000771]}\end{array}$ \\
\hline Log Tobin's Q (t-1) & & & & & $\begin{array}{l}0.0892 * * * \\
{[0.00338]} \\
\end{array}$ & $\begin{array}{l}0.0888^{* * *} \\
{[0.00337]} \\
\end{array}$ \\
\hline Firm Fixed Effects & $\begin{array}{l}v \\
v\end{array}$ & 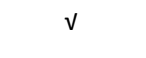 & $v$ & $v$ & $v$ & $v$ \\
\hline $\begin{array}{l}\text { Year Fixed Effects } \\
\text { Industry } \times \text { Year Fixed Effects }\end{array}$ & $\mathrm{v}$ & $\checkmark$ & $\sqrt{ }$ & $\sqrt{ }$ & $v$ & $\checkmark$ \\
\hline Observations & 93,741 & 93,741 & 93,741 & 93,741 & 93,741 & 93,741 \\
\hline R-squared & 0.081 & 0.391 & 0.404 & 0.405 & 0.427 & 0.427 \\
\hline Number of Firms & 10,445 & 10,445 & 10,445 & 10,445 & 10,445 & 10,445 \\
\hline
\end{tabular}

Notes: Standard errors are clustered at firm level. Dependent variable is calculated as $\log (\mathrm{K}(\mathrm{t}))-\log (\mathrm{K}(\mathrm{t}-1))$ where $\mathrm{K}$ is firm's total capital stock. Firm uncertainty measure CRUX is at time $t$, which as mentioned in the text captures firm uncertainty at time $t-1$ and we further define high CRUX as above median in the sample. Sales growth is calculated as $\log (\operatorname{Sales}(\mathrm{t}-1))-\log (\operatorname{Sales}(\mathrm{t}-2))$ and demeaned by sample mean. Squared sales growth is calculated using demeand sales growth. Tobin's $Q$ is taken as log average $Q$ at time t-1. All of the regression specifications include firm FE. Column (1) includes Year FE, Column (2)-(6) include industry $\times$ year FE, where industry is at 3-digit NAICS code level. Column (2)-(6) loses some observations and firms compared with Column (1) due to singleton observations. Time ranges from 1994 to 2016.

$* * * p<0.01,{ }^{* *} p<0.05, * p<0.1$ 
Table A7: Effects of "Risk" on Corporate Investment Rate ( $\Delta \ln$, Compustat)

\begin{tabular}{|c|c|c|c|c|c|c|}
\hline \multirow[b]{2}{*}{ VARIABLES } & \multicolumn{6}{|c|}{ Dependent Variable: Log Change in Capital Stock K $(\Delta \ln , \mathrm{t})$} \\
\hline & (1) & $(2)$ & (3) & (4) & (5) & $(6)$ \\
\hline RISK $(t)$ & $\begin{array}{c}0.0643 * * * \\
{[0.0171]}\end{array}$ & $\begin{array}{c}0.0353^{* *} \\
{[0.0167]}\end{array}$ & $\begin{array}{l}0.0280 * \\
{[0.0166]}\end{array}$ & $\begin{array}{l}0.0290 * \\
{[0.0166]}\end{array}$ & $\begin{array}{c}0.0257 \\
{[0.0163]}\end{array}$ & $\begin{array}{c}0.0265 \\
{[0.0163]}\end{array}$ \\
\hline Sales Growth $(\Delta \ln \mathrm{t}-1)$ & & & $\begin{array}{l}0.0594 * * * \\
{[0.00601]}\end{array}$ & $\begin{array}{l}0.0587^{* * *} \\
{[0.00602]}\end{array}$ & $\begin{array}{l}0.0569 * * * \\
{[0.00569]}\end{array}$ & $\begin{array}{l}0.0563^{* * *} \\
{[0.00570]}\end{array}$ \\
\hline RISK $(\mathrm{t}) \times$ Sales Growth $(\Delta \ln \mathrm{t}-1)$ & & & $\begin{array}{l}-0.0532 \\
{[0.0339]}\end{array}$ & $\begin{array}{l}-0.0573^{*} \\
{[0.0343]}\end{array}$ & $\begin{array}{c}-0.0676^{* *} \\
{[0.0327]}\end{array}$ & $\begin{array}{c}-0.0708^{* *} \\
{[0.0329]}\end{array}$ \\
\hline Sales Growth $(\Delta \ln t-1)$ sqaured & & & & $\begin{array}{l}0.00327^{* * *} \\
{[0.000839]}\end{array}$ & & $\begin{array}{l}0.00256^{* * *} \\
{[0.000775]}\end{array}$ \\
\hline Log Tobin's Q (t-1) & & & & & $\begin{array}{l}0.0898^{* * *} \\
{[0.00338]} \\
\end{array}$ & $\begin{array}{l}0.0894^{* * *} \\
{[0.00338]} \\
\end{array}$ \\
\hline $\begin{array}{l}\text { Firm Fixed Effects } \\
\text { Year Fixed Effects }\end{array}$ & $\begin{array}{l}v \\
v\end{array}$ & v & $v$ & $v$ & $v$ & $v$ \\
\hline Industry $\times$ Year Fixed Effects & & $\sqrt{ }$ & $\mathrm{v}$ & $\mathrm{v}$ & $\mathrm{v}$ & $\mathrm{v}$ \\
\hline Observations & 93,741 & 93,741 & 93,741 & 93,741 & 93,741 & 93,741 \\
\hline R-squared & 0.080 & 0.391 & 0.403 & 0.403 & 0.425 & 0.426 \\
\hline Number of Firms & 10,445 & 10,445 & 10,445 & 10,445 & 10,445 & 10,445 \\
\hline
\end{tabular}

Notes: Standard errors are clustered at firm level. Dependent variable is calculated as $\log (\mathrm{K}(\mathrm{t}))-\log (\mathrm{K}(\mathrm{t}-1))$ where $\mathrm{K}$ is firm's total capital stock. RISK is constructed by taking word risk and its derivatives following the same method as uncertainty. Sales growth is calculated as $\log ($ Sales $(t-1))-\log ($ Sales $(t-2))$ and demeaned by sample mean. Squared sales growth is calculated using demeand sales growth. Tobin's $Q$ is taken as log average $Q$ at time t-1. All of the regression specifications include firm FE. Column (1) includes Year FE, Column (2)-(6) include industry $\times$ year FE, where industry is at 3-digit NAICS code level. Column (2)-(6) loses some observations and firms compared with Column (1) due to singleton observations. Time ranges from 1994 to 2016.

*** $\mathrm{p}<0.01,{ }^{* *} \mathrm{p}<0.05, * \mathrm{p}<0.1$ 
Table A8: Effects of Realized Volatility vs CRUX on Corporate Investment Rate ( $\Delta \ln$, Compustat)

\begin{tabular}{|c|c|c|c|c|c|c|}
\hline \multirow[b]{2}{*}{ VARIABLES } & \multicolumn{6}{|c|}{ Dependent Variable: Log Change in Capital Stock K $(\Delta \ln , \mathrm{t})$} \\
\hline & (1) & $(2)$ & (3) & (4) & (5) & (6) \\
\hline $\operatorname{CRUX}(\mathrm{t})$ & $\begin{array}{c}-0.366 * * * \\
{[0.0443]}\end{array}$ & $\begin{array}{c}-0.319^{* * *} \\
{[0.0441]}\end{array}$ & $\begin{array}{c}-0.310^{* * *} \\
{[0.0433]}\end{array}$ & $\begin{array}{c}-0.312^{* * *} \\
{[0.0431]}\end{array}$ & $\begin{array}{c}-0.284^{* * *} \\
{[0.0409]}\end{array}$ & $\begin{array}{c}-0.285^{* * *} \\
{[0.0408]}\end{array}$ \\
\hline Sales Growth $(\Delta \ln \mathrm{t}-1)$ & & & $\begin{array}{c}0.0962^{* * *} \\
{[0.00853]}\end{array}$ & $\begin{array}{c}0.0910 * * * \\
{[0.00833]}\end{array}$ & $\begin{array}{c}0.0798 * * * \\
{[0.00784]}\end{array}$ & $\begin{array}{c}0.0752^{* * *} \\
{[0.00766]}\end{array}$ \\
\hline CRUX $(t) \times$ Sales Growth $(\Delta \ln t-1)$ & & & $\begin{array}{c}-0.587^{* * *} \\
{[0.102]}\end{array}$ & $\begin{array}{c}-0.567^{* * *} \\
{[0.100]}\end{array}$ & $\begin{array}{c}-0.555^{* * *} \\
{[0.0950]}\end{array}$ & $\begin{array}{c}-0.537^{* * *} \\
{[0.0934]}\end{array}$ \\
\hline Real Vol (t-1) & $\begin{array}{c}0.0164 \\
{[0.0132]}\end{array}$ & $\begin{array}{l}-0.00372 \\
{[0.0128]}\end{array}$ & $\begin{array}{l}0.00210 \\
{[0.0135]}\end{array}$ & $\begin{array}{c}0.000672 \\
{[0.0135]}\end{array}$ & $\begin{array}{c}-0.0413^{* * *} \\
{[0.0127]}\end{array}$ & $\begin{array}{c}-0.0425^{* * *} \\
{[0.0127]}\end{array}$ \\
\hline Real Vol $(\mathrm{t}-1) \times$ Sales Growth $(\Delta \ln \mathrm{t}-1)$ & & & $\begin{array}{l}0.00447 \\
{[0.0175]}\end{array}$ & $\begin{array}{c}0.0143 \\
{[0.0172]}\end{array}$ & $\begin{array}{l}0.00758 \\
{[0.0149]}\end{array}$ & $\begin{array}{c}0.0165 \\
{[0.0149]}\end{array}$ \\
\hline Sales Growth $(\Delta \ln t-1)$ sqaured & & & & $\begin{array}{c}0.00517 * * * \\
{[0.00132]}\end{array}$ & & $\begin{array}{c}0.00468 * * * \\
{[0.00118]}\end{array}$ \\
\hline Log Tobin's Q (t-1) & & & & & $\begin{array}{l}0.128 * * * \\
{[0.00356]} \\
\end{array}$ & $\begin{array}{l}0.128 * * * \\
{[0.00355]}\end{array}$ \\
\hline $\begin{array}{l}\text { Firm Fixed Effects } \\
\text { Year Fixed Effects }\end{array}$ & $\begin{array}{l}v \\
v\end{array}$ & $\mathrm{v}$ & $\mathrm{v}$ & $v$ & $\mathrm{v}$ & $v$ \\
\hline Industry $\times$ Year Fixed Effects & & $\mathrm{v}$ & $\mathrm{v}$ & $\mathrm{v}$ & $\mathrm{v}$ & $\mathrm{v}$ \\
\hline Observations & 72,606 & 72,606 & 72,606 & 72,606 & 72,606 & 72,606 \\
\hline R-squared & 0.097 & 0.422 & 0.439 & 0.440 & 0.477 & 0.478 \\
\hline Number of Firms & 8,023 & 8,023 & 8,023 & 8,023 & 8,023 & 8,023 \\
\hline
\end{tabular}

Notes: Standard errors are clustered at firm level. Dependent variable is calculated as $\log (K(t))-\log (K(t-1))$ where $K$ is firm's total capital stock.

Firm uncertainty measure CRUX is at time $t$, which as mentioned in the text captures firm uncertainty at time $\mathrm{t}-1$. Realized Volatility is calculated as the standard deviation of firms' monthly stock returns at $\mathrm{t}-1$. Sales growth is calculated as $\log (\operatorname{Sales}(\mathrm{t}-1))-\log (\operatorname{Sales}(\mathrm{t}-2))$ and demeaned by sample mean. Squared sales growth is calculated using demeand sales growth. Tobin's $Q$ is taken as log average $Q$ at time $t-1$. All of the regression specifications include firm FE. Column (1) includes Year FE, Column (2)-(6) include industry $\times$ year FE, where industry is at 3-digit NAICS code level. Column (2)-(6) loses some observations and firms compared with Column (1) due to singleton observations. Time ranges from 1994 to 2016.

*** $p<0.01,{ }^{* *} p<0.05, * p<0.1$ 
Table A9: Effects of Implied Volatility vs CRUX on Corporate Investment Rate ( $\Delta \ln$, Compustat)

\begin{tabular}{|c|c|c|c|c|c|c|}
\hline \multirow[b]{2}{*}{ VARIABLES } & \multicolumn{6}{|c|}{ Dependent Variable: Log Change in Capital Stock $K(\Delta \ln , t)$} \\
\hline & (1) & $(2)$ & (3) & (4) & (5) & (6) \\
\hline $\operatorname{CRUX}(\mathrm{t})$ & $\begin{array}{c}-0.402 * * * \\
{[0.0587]}\end{array}$ & $\begin{array}{c}-0.373 * * * \\
{[0.0576]}\end{array}$ & $\begin{array}{c}-0.357 * * * \\
{[0.0562]}\end{array}$ & $\begin{array}{c}-0.357^{* * *} \\
{[0.0562]}\end{array}$ & $\begin{array}{c}-0.314^{* * *} \\
{[0.0540]}\end{array}$ & $\begin{array}{c}-0.314^{* * *} \\
{[0.0540]}\end{array}$ \\
\hline Sales Growth $(\Delta \ln \mathrm{t}-1)$ & & & $\begin{array}{c}0.111^{* * *} \\
{[0.0113]}\end{array}$ & $\begin{array}{c}0.111^{* * *} \\
{[0.0107]}\end{array}$ & $\begin{array}{c}0.0895 * * * \\
{[0.00971]}\end{array}$ & $\begin{array}{c}0.0884 * * * \\
{[0.00905]}\end{array}$ \\
\hline $\operatorname{CRUX}(\mathrm{t}) \times$ Sales Growth $(\Delta \ln \mathrm{t}-1)$ & & & $\begin{array}{c}-0.789 * * * \\
{[0.136]}\end{array}$ & $\begin{array}{c}-0.788 * * * \\
{[0.133]}\end{array}$ & $\begin{array}{c}-0.703^{* * *} \\
{[0.118]}\end{array}$ & $\begin{array}{c}-0.691 * * * \\
{[0.115]}\end{array}$ \\
\hline Impl Vol (t-1) & $\begin{array}{c}-0.00106 \\
{[0.00153]}\end{array}$ & $\begin{array}{l}-0.00162 \\
{[0.00139]}\end{array}$ & $\begin{array}{c}-0.00222 * \\
{[0.00129]}\end{array}$ & $\begin{array}{c}-0.00223^{*} \\
{[0.00130]}\end{array}$ & $\begin{array}{c}-0.00181 * * \\
{[0.000901]}\end{array}$ & $\begin{array}{c}-0.00183^{* *} \\
{[0.000913]}\end{array}$ \\
\hline Impl Vol (t-1) $\times$ Sales Growth $(\Delta \ln \mathrm{t}-1)$ & & & $\begin{array}{l}0.000167 \\
{[0.00133]}\end{array}$ & $\begin{array}{l}0.000168 \\
{[0.00133]}\end{array}$ & $\begin{array}{c}0.000584 \\
{[0.000948]}\end{array}$ & $\begin{array}{c}0.000591 \\
{[0.000951]}\end{array}$ \\
\hline Sales Growth $(\Delta \ln \mathrm{t}-1)$ sqaured & & & & $\begin{array}{l}0.000153 \\
{[0.00246]}\end{array}$ & & $\begin{array}{c}0.00113 \\
{[0.00214]}\end{array}$ \\
\hline Log Tobin's Q (t-1) & & & & & $\begin{array}{l}0.121^{* * *} \\
{[0.00502]}\end{array}$ & $\begin{array}{l}0.121^{* * *} \\
{[0.00501]} \\
\end{array}$ \\
\hline Firm Fixed Effects & $\mathrm{v}$ & $\mathrm{v}$ & $\mathrm{v}$ & $\mathrm{v}$ & $\mathrm{v}$ & $\mathrm{v}$ \\
\hline Year Fixed Effects & $\mathrm{v}$ & & & & & \\
\hline Industry $\times$ Year Fixed Effects & & $\sqrt{ }$ & 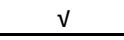 & $\checkmark$ & $\checkmark$ & $v$ \\
\hline Observations & 34,202 & 34,202 & 34,202 & 34,202 & 34,202 & 34,202 \\
\hline R-squared & 0.123 & 0.498 & 0.517 & 0.517 & 0.558 & 0.558 \\
\hline Number of Firms & 4,156 & 4,156 & 4,156 & 4,156 & 4,156 & 4,156 \\
\hline
\end{tabular}

Notes: Standard errors are clustered at firm level. Dependent variable is calculated as $\log (\mathrm{K}(\mathrm{t}))-\log (\mathrm{K}(\mathrm{t}-1))$ where $\mathrm{K}$ is firm's total capital stock. Firm uncertainty measure CRUX is at time $t$, which as mentioned in the text captures firm uncertainty at time t-1. The implied volatility is calculated following Barrero, Bloom and Wright (2017) by year using 91 day duration daily implied volatility. Sales growth is calculated as $\log ($ Sales $(\mathrm{t}-1))-\log ($ Sales$(\mathrm{t}-2))$ and demeaned by sample mean. Squared sales growth is calculated using demeand sales growth. Tobin's $Q$ is taken as log average $Q$ at time t-1. All of the regression specifications include firm FE. Column (1) includes Year FE, Column (2)-(6) include industry $\times$ year $\mathrm{FE}$, where industry is at 3-digit NAICS code level. Column (2)-(6) loses some observations and firms compared with Column (1) due to singleton observations. Time ranges from 1997 to 2016.

*** $p<0.01,{ }^{* *} p<0.05, * p<0.1$ 
Table A10: Effects of Uncertainty on Corporate Investment Rate (Alternative Investment Measures, Compustat)

\begin{tabular}{|c|c|c|c|c|c|c|c|c|}
\hline \multirow[b]{3}{*}{ VARIABLES } & \multicolumn{4}{|c|}{ Panel A } & \multicolumn{4}{|c|}{ Panel B } \\
\hline & \multicolumn{2}{|c|}{$\log (1 / K)(t)$} & \multicolumn{2}{|c|}{$\mathrm{I} / \mathrm{K}(\mathrm{t})$} & \multicolumn{2}{|c|}{$\log (\mathrm{I} / \mathrm{K})(\mathrm{t})$} & \multicolumn{2}{|c|}{$\mathrm{I} / \mathrm{K}(\mathrm{t})$} \\
\hline & $(1)$ & $(2)$ & (3) & $(4)$ & $(5)$ & $(6)$ & $(7)$ & $(8)$ \\
\hline $\operatorname{CRUX}(\mathrm{t})$ & $\begin{array}{c}-1.475^{* * *} \\
{[0.187]}\end{array}$ & $\begin{array}{c}-1.408 * * * \\
{[0.181]}\end{array}$ & $\begin{array}{c}-0.139 * * * \\
{[0.0228]}\end{array}$ & $\begin{array}{c}-0.133^{* * *} \\
{[0.0222]}\end{array}$ & $\begin{array}{c}-0.812 * * * \\
{[0.159]}\end{array}$ & $\begin{array}{c}-0.766 * * * \\
{[0.155]}\end{array}$ & $\begin{array}{c}-0.167^{* * *} \\
{[0.0358]}\end{array}$ & $\begin{array}{c}-0.157^{* * *} \\
{[0.0351]}\end{array}$ \\
\hline Sales Growth $(\Delta \ln \mathrm{t}-1)$ & & $\begin{array}{c}0.183 * * * \\
{[0.0161]}\end{array}$ & & $\begin{array}{c}0.0237^{* * *} \\
{[0.00228]}\end{array}$ & & $\begin{array}{c}0.111^{* * *} \\
{[0.0136]}\end{array}$ & & $\begin{array}{c}0.0267 * * * \\
{[0.00322]}\end{array}$ \\
\hline CRUX $(\mathrm{t}) \times$ Sales Growth $(\Delta \ln \mathrm{t}-1)$ & & $\begin{array}{c}-0.518^{* *} \\
{[0.252]}\end{array}$ & & $\begin{array}{c}-0.136 * * * \\
{[0.0362]}\end{array}$ & & $\begin{array}{c}-0.472^{* *} \\
{[0.214]}\end{array}$ & & $\begin{array}{c}-0.172 * * * \\
{[0.0536]}\end{array}$ \\
\hline Log Tobin's Q (t-1) & & $\begin{array}{c}0.346 * * * \\
{[0.0115]}\end{array}$ & & $\begin{array}{c}0.0449 * * * \\
{[0.00159]}\end{array}$ & & $\begin{array}{l}0.299 * * * \\
{[0.00976]}\end{array}$ & & $\begin{array}{c}0.0671 * * * \\
{[0.00227]}\end{array}$ \\
\hline Firm Fixed Effects & $\mathrm{V}$ & $v$ & $v$ & $\mathrm{~V}$ & $v$ & 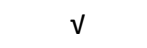 & $v$ & $v$ \\
\hline Industry $\times$ Year Fixed Effects & $\mathrm{V}$ & $\sqrt{ }$ & $\mathrm{v}$ & $\mathrm{V}$ & $v$ & $\sqrt{ }$ & $v$ & $\sqrt{ }$ \\
\hline Observations & 91,246 & 91,246 & 93,397 & 93,397 & 98,361 & 98,361 & 100,659 & 100,659 \\
\hline R-squared & 0.491 & 0.517 & 0.441 & 0.469 & 0.532 & 0.549 & 0.499 & 0.518 \\
\hline Number of Firms & 10,128 & 10,128 & 10,305 & 10,305 & 11,008 & 11,008 & 11,198 & 11,198 \\
\hline
\end{tabular}

Notes: Standard errors are clustered at firm level. Dependent variables in columns (1)-(2) and (5)-(6) are calculated as log $(\mathrm{I}(\mathrm{t}) / \mathrm{K}(\mathrm{t}))$ and dependent variables in columns (3)-(4) and (7)-(8) are calculated as $\mathrm{I}(\mathrm{t}) / \mathrm{K}(\mathrm{t})$, where $\mathrm{I}$ is capital expenditure (capx) and $\mathrm{K}$ is firm's total gross property, plant and equipment (ppegt) in Panel A and firm's net gross property, plant and equipment (ppent) in Panel B. Dependent variables in columns (3)-(4) and (7)-(8) are winsorized by $1 \%$ and $99 \%$. Firm uncertainty measure CRUX is at time t, which as mentioned in the text captures firm uncertainty at time $t-1$. Sales growth is calculated as $\log (\operatorname{Sales}(\mathrm{t}-1))-\log (\operatorname{Sales}(\mathrm{t}-2))$ and demeaned by sample mean. Tobin's $Q$ is taken as log average $\mathrm{Q}$ at time $\mathrm{t}-1$. All of the regression specifications include firm and industry $\times$ year FE, where industry is at 3-digit NAICS code level. Time ranges from 1994 to 2016.

$* * * \mathrm{p}<0.01, * * \mathrm{p}<0.05, * \mathrm{p}<0.1$ 
Table A11: Effects of Post 2006 Indicator vs CRUX on Corporate Investment Rate ( $\Delta$ ln, Compustat)

\begin{tabular}{|c|c|c|c|c|c|c|}
\hline \multirow[b]{2}{*}{ VARIABLES } & \multicolumn{6}{|c|}{ Dependent Variable: Log Change in Capital Stock K $(\Delta \ln , \mathrm{t})$} \\
\hline & $(1)$ & $(2)$ & (3) & $(4)$ & $(5)$ & (6) \\
\hline \multirow[t]{2}{*}{$\operatorname{CRUX}(\mathrm{t})$} & $-0.299 * * *$ & $-0.305 * * *$ & $-0.276 * * *$ & $-0.280 * * *$ & $-0.275^{* * *}$ & $-0.279 * * *$ \\
\hline & {$[0.0573]$} & {$[0.0573]$} & {$[0.0562]$} & {$[0.0562]$} & {$[0.0550]$} & {$[0.0550]$} \\
\hline \multirow[t]{2}{*}{ CRUX $(t) \times$ Post 2006} & -0.110 & -0.0100 & -0.0630 & -0.0570 & -0.0561 & -0.0515 \\
\hline & [0.0694] & [0.0701] & {$[0.0685]$} & {$[0.0685]$} & {$[0.0674]$} & {$[0.0674]$} \\
\hline \multirow[t]{2}{*}{$\operatorname{CRUX}(\mathrm{t}) \times$ Sales Growth $(\Delta \ln \mathrm{t}-1)$} & & & $-0.383 * * *$ & $-0.368 * * *$ & $-0.377 * * *$ & $-0.366 * * *$ \\
\hline & & & {$[0.0753]$} & {$[0.0760]$} & {$[0.0742]$} & {$[0.0747]$} \\
\hline \multirow[t]{2}{*}{ CRUX $(\mathrm{t}) \times$ Sales Growth $(\Delta \ln \mathrm{t}-1) \times$ Post 2006} & & & $-0.214 * * *$ & $-0.214 * * *$ & $-0.152^{*}$ & $-0.153^{*}$ \\
\hline & & & {$[0.0818]$} & [0.0829] & {$[0.0815]$} & {$[0.0822]$} \\
\hline \multirow[t]{2}{*}{ Sales Growth ( $\Delta$ ln t-1) } & & & $0.0769 * * *$ & $0.0750 * * *$ & $0.0708^{* * *}$ & $0.0694 * * *$ \\
\hline & & & {$[0.00542]$} & {$[0.00529]$} & {$[0.00518]$} & {$[0.00508]$} \\
\hline \multirow[t]{2}{*}{ Sales Growth $(\Delta \ln \mathrm{t}-1)$ sqaured } & & & & $0.00299 * * *$ & & $0.00229 * * *$ \\
\hline & & & & {$[0.000827]$} & & {$[0.000767]$} \\
\hline \multirow[t]{2}{*}{ Log Tobin's Q (t-1) } & & & & & $0.0891 * * *$ & $0.0888^{* * *}$ \\
\hline & & & & & {$[0.00337]$} & {$[0.00337]$} \\
\hline Firm Fixed Effects & $\sqrt{ }$ & $\sqrt{ }$ & $\sqrt{ }$ & $\sqrt{ }$ & $\sqrt{ }$ & $\sqrt{ }$ \\
\hline Year Fixed Effects & $v$ & & & & & \\
\hline Industry $\times$ Year Fixed Effects & & V & V & $\sqrt{ }$ & $\mathrm{V}$ & $\mathrm{V}$ \\
\hline Observations & 95,222 & 93,741 & 93,741 & 93,741 & 93,741 & 93,741 \\
\hline R-squared & 0.081 & 0.391 & 0.405 & 0.405 & 0.427 & 0.427 \\
\hline Number of Firms & 11,864 & 10,445 & 10,445 & 10,445 & 10,445 & 10,445 \\
\hline \multicolumn{7}{|c|}{$\begin{array}{l}\text { Notes: Standard errors are clustered at firm level. Dependent variable is calculated as } \log (\mathrm{K}(\mathrm{t}))-\log (\mathrm{K}(\mathrm{t}-1)) \text { where } \mathrm{K} \text { is firm's total capital stock. Firm } \\
\text { uncertainty measure CRUX is at time } \mathrm{t} \text {, which as mentioned in the text captures firm uncertainty at time t- } 1 \text {. Post } 2006 \text { is an indicator equals to } 1 \text { if fiscal } \\
\text { year is after } 2006 \text {, and } 0 \text { otherwise. Sales growth is calculated as } \log (\operatorname{Sales}(\mathrm{t}-1))-\log (\mathrm{Sales}(\mathrm{t}-2)) \text { and demeaned by sample mean. Squared sales growth is } \\
\text { calculated using demeand sales growth. Tobin's } Q \text { is taken as } \log \text { average } Q \text { at time } t-1 \text {. All of the regression specifications include firm FE. Column (1) } \\
\text { includes Year FE, Column (2)-(6) include industry } \times \text { year FE, where industry is at 3-digit NAICS code level. Column (2)-(6) loses some observations and } \\
\text { firms compared with Column (1) due to singleton observations. Time ranges from } 1994 \text { to } 2016 \text {. } \\
* * * p<0.01, * * p<0.05, * p<0.1\end{array}$} \\
\hline
\end{tabular}


Table A12: Effects of Risk Factors vs CRUX on Corporate Investment Rate ( $\Delta \ln$, Compustat)

\begin{tabular}{|c|c|c|c|c|c|c|}
\hline \multirow[b]{2}{*}{ VARIABLES } & \multicolumn{6}{|c|}{ Dependent Variable: Log Change in Capital Stock K $(\Delta \ln , \mathrm{t})$} \\
\hline & (1) & $(2)$ & (3) & (4) & (5) & (6) \\
\hline $\operatorname{CRUX}(\mathrm{t})$ & $\begin{array}{c}-0.198 * * * \\
{[0.0639]}\end{array}$ & $\begin{array}{c}-0.230 * * * \\
{[0.0633]}\end{array}$ & $\begin{array}{c}-0.220 * * * \\
{[0.0632]}\end{array}$ & $\begin{array}{c}-0.222 * * * \\
{[0.0632]}\end{array}$ & $\begin{array}{c}-0.241 * * * \\
{[0.0614]}\end{array}$ & $\begin{array}{c}-0.243 * * * \\
{[0.0613]}\end{array}$ \\
\hline Risk Factors (t) & $\begin{array}{c}0.0424 * * * \\
{[0.00446]}\end{array}$ & $\begin{array}{l}0.0327 * * * \\
{[0.00446]}\end{array}$ & $\begin{array}{c}0.0303 * * * \\
{[0.00433]}\end{array}$ & $\begin{array}{l}0.0301 * * * \\
{[0.00433]}\end{array}$ & $\begin{array}{c}0.0254 * * * \\
{[0.00421]}\end{array}$ & $\begin{array}{c}0.0252 * * * \\
{[0.00421]}\end{array}$ \\
\hline $\operatorname{CRUX}(\mathrm{t}) \times$ Risk Factors $(\mathrm{t})$ & $\begin{array}{c}-0.257 * * * \\
{[0.0734]}\end{array}$ & $\begin{array}{l}-0.141^{*} \\
{[0.0738]}\end{array}$ & $\begin{array}{l}-0.140 * \\
{[0.0734]}\end{array}$ & $\begin{array}{l}-0.139 * \\
{[0.0733]}\end{array}$ & $\begin{array}{c}-0.101 \\
{[0.0714]}\end{array}$ & $\begin{array}{c}-0.101 \\
{[0.0713]}\end{array}$ \\
\hline $\operatorname{CRUX}(\mathrm{t}) \times$ Sales Growth $(\Delta \ln \mathrm{t}-1)$ & & & $\begin{array}{c}-0.499 * * * \\
{[0.0847]}\end{array}$ & $\begin{array}{c}-0.466 * * * \\
{[0.0852]}\end{array}$ & $\begin{array}{c}-0.473^{* * *} \\
{[0.0836]}\end{array}$ & $\begin{array}{c}-0.448^{* * *} \\
{[0.0841]}\end{array}$ \\
\hline CRUX $(\mathrm{t}) \times$ Sales Growth $(\Delta \ln \mathrm{t}-1) \times$ Risk Factors $(\mathrm{t})$ & & & $\begin{array}{l}0.00676 \\
{[0.0804]}\end{array}$ & $\begin{array}{c}-0.0173 \\
{[0.0809]}\end{array}$ & $\begin{array}{c}0.0222 \\
{[0.0801]}\end{array}$ & $\begin{array}{l}0.00378 \\
{[0.0805]}\end{array}$ \\
\hline Sales Growth ( $\Delta \ln \mathrm{t}-1)$ & & & $\begin{array}{l}0.0773 * * * \\
{[0.00545]}\end{array}$ & $\begin{array}{c}0.0754 * * * \\
{[0.00532]}\end{array}$ & $\begin{array}{l}0.0710^{* * *} \\
{[0.00520]}\end{array}$ & $\begin{array}{c}0.0696 * * * \\
{[0.00510]}\end{array}$ \\
\hline Sales Growth ( $\Delta \ln \mathrm{t}-1)$ sqaured & & & & $\begin{array}{l}0.00296 * * * \\
{[0.000822]}\end{array}$ & & $\begin{array}{l}0.00227 * * * \\
{[0.000762]}\end{array}$ \\
\hline Log Tobin's Q (t-1) & & & & & $\begin{array}{c}0.0890 * * * \\
{[0.00338]}\end{array}$ & $\begin{array}{c}0.0886 * * * \\
{[0.00337]} \\
\end{array}$ \\
\hline $\begin{array}{l}\text { Firm Fixed Effects } \\
\text { Year Fixed Effects }\end{array}$ & $\begin{array}{l}v \\
v\end{array}$ & $\checkmark$ & $\checkmark$ & V & $\checkmark$ & $v$ \\
\hline Industry $\times$ Year Fixed Effects & & $\checkmark$ & 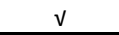 & $\sqrt{ }$ & $\checkmark$ & $\mathrm{v}$ \\
\hline Observations & 93,741 & 93,741 & 93,741 & 93,741 & 93,741 & 93,741 \\
\hline R-squared & 0.083 & 0.392 & 0.405 & 0.406 & 0.427 & 0.428 \\
\hline Number of Firms & 10,445 & 10,445 & 10,445 & 10,445 & 10,445 & 10,445 \\
\hline
\end{tabular}

Notes: Standard errors are clustered at firm level. Dependent variable is calculated as $\log (\mathrm{K}(\mathrm{t}))-\log (\mathrm{K}(\mathrm{t}-1))$ where $\mathrm{K}$ is firm's total capital stock. Firm uncertainty measure CRUX is at time $t$, which as mentioned in the text captures firm uncertainty at time t-1. Risk Factors is an indicator equals to 1 if firm reports item $1 \mathrm{~A}$ risk factors section during the year, and 0 otherwise. Sales growth is calculated as $\log (\operatorname{Sales}(\mathrm{t}-1))-\log (\operatorname{Sales}(\mathrm{t}-2))$ and demeaned by sample mean. Squared sales growth is calculated using demeand sales growth. Tobin's $Q$ is taken as log average $Q$ at time $t-1$. All of the regression specifications include firm FE. Column (1) includes Year FE, Column (2)-(6) include industry $\times$ year FE, where industry is at 3-digit NAICS code level. Column (2)-(6) loses some observations and firms compared with Column (1) due to singleton observations. Time ranges from 1994 to 2016.

*** $\mathrm{p}<0.01, * * \mathrm{p}<0.05, * \mathrm{p}<0.1$ 
Table A13: Effect of Uncertainty on Manufacturing Establishment Level Investment Rate $(\Delta \ln )$ and Investment Spikes - IPS Weighted Regression

\begin{tabular}{|c|c|c|c|c|c|c|}
\hline \multirow[b]{2}{*}{ VARIABLES } & \multicolumn{3}{|c|}{ Log Total Investment Rate $(\Delta \ln , \mathrm{t})$} & \multicolumn{3}{|c|}{ Investment Spike (t) } \\
\hline & (1) & (2) & (3) & (4) & (5) & (6) \\
\hline $\operatorname{CRUX}(\mathrm{t})$ & $\begin{array}{l}-0.0630 * \\
{[0.0345]}\end{array}$ & $\begin{array}{l}-0.0608^{*} \\
{[0.0346]}\end{array}$ & & $\begin{array}{c}-0.0997^{*} \\
{[0.0530]}\end{array}$ & $\begin{array}{l}-0.0972 * \\
{[0.0528]}\end{array}$ & \\
\hline TVS Growth $(\Delta \ln t-1)$ & $\begin{array}{l}0.0447 * * * \\
{[0.00665]}\end{array}$ & $\begin{array}{c}0.0424 * * * \\
{[0.00624]}\end{array}$ & $\begin{array}{c}0.0437 * * * \\
{[0.00615]}\end{array}$ & $\begin{array}{c}0.0400 * * * \\
{[0.00493]}\end{array}$ & $\begin{array}{c}0.0370 * * * \\
{[0.00474]}\end{array}$ & $\begin{array}{c}0.0369 * * * \\
{[0.00475]}\end{array}$ \\
\hline $\operatorname{CRUX}(\mathrm{t}) \times$ TVS Growth $(\Delta \ln \mathrm{t}-1)$ & $\begin{array}{c}-0.311^{* * *} \\
{[0.107]}\end{array}$ & $\begin{array}{c}-0.294 * * * \\
{[0.104]}\end{array}$ & $\begin{array}{c}-0.336 * * * \\
{[0.111]}\end{array}$ & $\begin{array}{c}-0.274 * * * \\
{[0.0892]}\end{array}$ & $\begin{array}{c}-0.251 * * * \\
{[0.0876]}\end{array}$ & $\begin{array}{c}-0.272^{* * *} \\
{[0.0918]}\end{array}$ \\
\hline TVS Growth $(\Delta \ln \mathrm{t}-1)$ squared & & $\begin{array}{c}0.00538 * * * \\
{[0.00174]}\end{array}$ & $\begin{array}{c}0.00491^{* * *} \\
{[0.00176]}\end{array}$ & & $\begin{array}{c}0.00702 * * * \\
{[0.00143]}\end{array}$ & $\begin{array}{c}0.00619 * * * \\
{[0.00135]}\end{array}$ \\
\hline Log Tobin's Q (t-1) & & $\begin{array}{c}0.0155^{* * *} \\
{[0.00318]} \\
\end{array}$ & & & $\begin{array}{c}0.0164 * * * \\
{[0.00509]} \\
\end{array}$ & \\
\hline Firm Fixed Effects & $v$ & v & & $v$ & $v$ & \\
\hline Firm $\times$ Year Fixed Effects & & & $\mathrm{v}$ & & & $\mathrm{v}$ \\
\hline Industry $\times$ Year Fixed Effects & $\sqrt{ }$ & $\sqrt{ }$ & $v$ & $\sqrt{ }$ & $\sqrt{ }$ & v \\
\hline R-squared & 0.071 & 0.073 & 0.215 & 0.071 & 0.073 & 0.215 \\
\hline $\begin{array}{l}\text { Notes: Standard errors are clust } \\
\text { establishment's total capital sto } \\
\text { otherwise, where } K \text { is establishm } \\
\text { captures firm uncertainty at time } \\
\text { and demeaned by sample mean. } \\
Q \text { at time } t-1 \text {. Columns (1)-( } 2 \text { ) and } \\
Q \text { (t- } 1) \text {. All columns include indus } \\
\text { score constructed by fitting logit } \\
2000 \text {, both rounded to the neare } \\
* * * p<0.01, * * p<0.05,{ }^{*} p<0.1\end{array}$ & $\begin{array}{l}\text { Dd at firm lev } \\
\text { Dependent } \\
\text { t's total capit } \\
\text { 1. Establishm } \\
\text { uared TVS gr } \\
\text {-(5) include } \\
\times \text { year FE, wh } \\
\text { ecifications.T } \\
\text { housands. }\end{array}$ & $\begin{array}{l}\text { Dependent va } \\
\text { iable in colun } \\
\text { tock. Firm leve } \\
\text { level TVS (tot } \\
\text { h is calculated } \\
\text { FE. Columns } \\
\text { industry is at } \\
\text { ranges from }\end{array}$ & $\begin{array}{l}\text { ole in columns } \\
\text { (4)-(6) is an } \\
\text { ncertainty me } \\
\text { value of shipm } \\
\text { ing demeand } \\
\text { and (6) includ } \\
\text { digit NAICS coc } \\
8 \text { to } 2014 \text {. Nu }\end{array}$ & $\begin{array}{l}\text { is calculated } \\
\text { tor = } 1 \text { if (K( } \\
\text { CRUX is at tim } \\
\text { owth is calcu } \\
\text { owth. Firm les } \\
\times \text { year FE, whi } \\
\text { I. Regressions } \\
\text { of observatior }\end{array}$ & $\begin{array}{l}\log (K(t))-\log ( \\
\langle(t-1)) / K(t-1) \\
\text { which as men } \\
d \text { as } \log (T V S(t- \\
\text { obin's } Q \text { is tak } \\
\text { bsorbs CRUX ( } \\
\text { weighted by ir } \\
133000 \text { and } n\end{array}$ & $\begin{array}{l}-1)) \text { where } \mathrm{K} \text { is } \\
0 \% \text { and }=0 \text { if } \\
\text { ned in the text } \\
-\log (\mathrm{TVS}(\mathrm{t}-2)) \\
\text { as } \log \text { average } \\
\text { and Log Tobin's } \\
\text { rse propensity } \\
\text { aber of firms is }\end{array}$ \\
\hline
\end{tabular}


Table A14: Effect of Uncertainty on Firm Employment Growth Rate Decomposition ( $\Delta$ DHS) - IPS Weighted Regression

\begin{tabular}{|c|c|c|c|c|c|c|c|c|}
\hline \multirow{4}{*}{ VARIABLES } & \multicolumn{8}{|c|}{ Dependent Variable: DHS Change in Employment ( $\Delta$ dhs, $\mathrm{t})$} \\
\hline & \multirow[t]{2}{*}{$(1)$} & $(2)$ & (3) & (4) & (5) & (6) & (7) & (8) \\
\hline & & \multicolumn{4}{|c|}{ Extensive Margin } & \multicolumn{3}{|c|}{ Continuer } \\
\hline & Total & Birth & Death & Acquisition & Divestiture & Net & Creation & Destruction \\
\hline \multirow[t]{2}{*}{$\operatorname{CRUX}(\mathrm{t})$} & $-0.225 * *$ & $-0.113^{* * *}$ & -0.0507 & -0.0405 & $0.0882 *$ & $-0.108 * *$ & $-0.0630 * *$ & -0.0451 \\
\hline & [0.0932] & [0.0337] & {$[0.0530]$} & [0.0303] & [0.0474] & {$[0.0517]$} & {$[0.0316]$} & {$[0.0378]$} \\
\hline \multirow[t]{2}{*}{ Sales Growth ( $\Delta \ln \mathrm{t}-1)$} & $0.148^{* * *}$ & $0.0193 * * *$ & $0.0358 * * *$ & $0.0232 * * *$ & 0.00442 & $0.0652 * * *$ & $0.0350 * * *$ & $0.0301 * * *$ \\
\hline & {$[0.0161]$} & {$[0.00363]$} & {$[0.00821]$} & {$[0.00368]$} & {$[0.00881]$} & [0.0107] & {$[0.00452]$} & {$[0.00819]$} \\
\hline \multirow[t]{2}{*}{ CRUX $(t) \times$ Sales Growth $(\Delta \ln t-1)$} & $-0.543 * *$ & $-0.156 * * *$ & -0.152 & $-0.189 * * *$ & 0.0439 & -0.0907 & $-0.152 * *$ & 0.0614 \\
\hline & {$[0.245]$} & {$[0.0469]$} & {$[0.164]$} & {$[0.0469]$} & {$[0.138]$} & {$[0.170]$} & {$[0.0600]$} & [0.139] \\
\hline R-squared & 0.268 & 0.253 & 0.278 & 0.257 & 0.257 & 0.203 & 0.248 & 0.241 \\
\hline
\end{tabular}

Notes: Standard errors are clustered at firm level. Regressions are weighted by inverse propensity score constructed by fitting logit specifications. Dependent variable is calculated as (emp(t)-emp(t-1))/ $(0.5 \times(\mathrm{emp}(\mathrm{t})+\mathrm{emp}(\mathrm{t}-1)))$ in different margins. Column (1) represents firm's total employment change. Columns (2)-(5) represent firm's employment change from establishment birth, death, acquisition and divestiture. Column (6) represents gross employment change from firm's continuing establishments. Columns (7)-(8) represent job creation and destruction in firm's continuing establishments. Coefficients in Columns (2)-(6) should add up to coefficients in Column (1). Coefficients in Columns (7)-(8) should add up to coefficients in Column (6). Firm uncertainty measure CRUX is at time t, which as mentioned in the text captures firm uncertainty at time $\mathrm{t}-1$. Sales growth is calculated as $\log (\operatorname{Sales}(\mathrm{t}-1))-\log (\mathrm{Sales}(\mathrm{t}-2))$ and demeaned by sample mean. All of the regression specifications include firm FE and industry $\times$ year FE, where industry is at 3-digit NAICS code level. Time ranges from 1994 to 2014 . Number of observations is 55000 and number of firms is 6000 , both rounded to the nearest thousands.

$* * * p<0.01, * * p<0.05, * p<0.1$ 